ص ص ص

$$
\begin{aligned}
& \text { تقدير فجوة الطلب على الطاقة الكهربائية للقطاع السكني }
\end{aligned}
$$

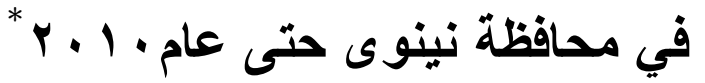

$$
\begin{aligned}
& \text { يسرى حازم جاسم الحيالي } \\
& \text { قسم الاقتصاد } \\
& \text { الدكتور أنمار أمين حاجي البرواري } \\
& \text { أستاذ مساعد - قسم الاقتصاد } \\
& \text { كلية الإدارة و الاقتصاد - جامعة الموصل }
\end{aligned}
$$

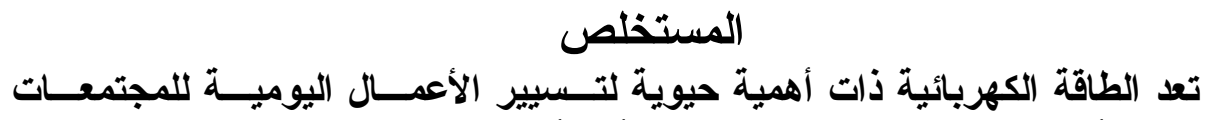

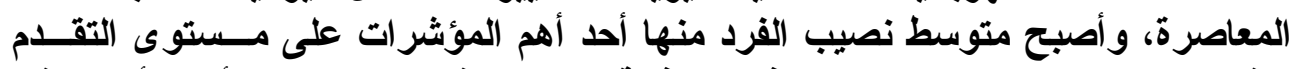

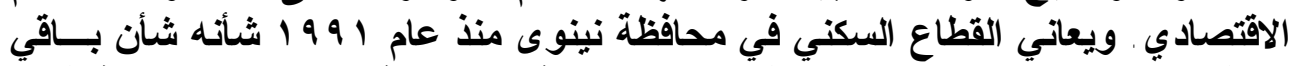

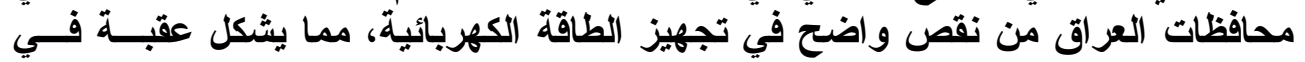

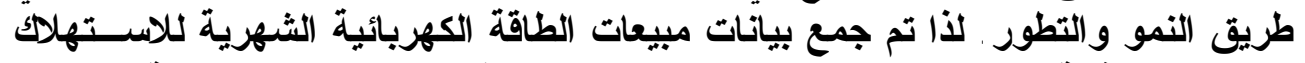

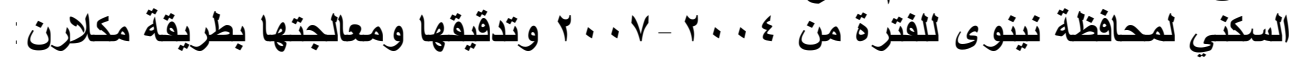

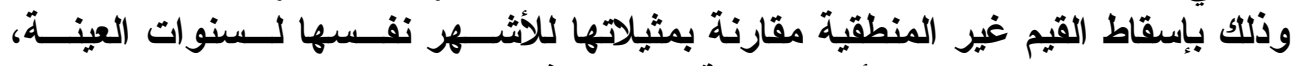

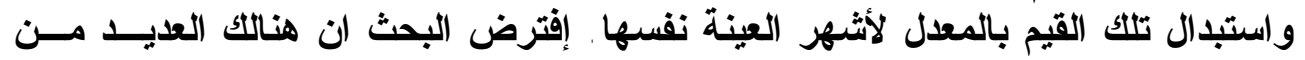

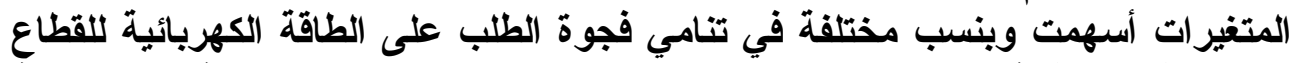

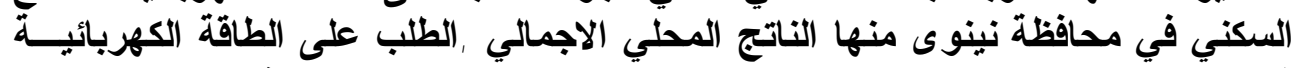

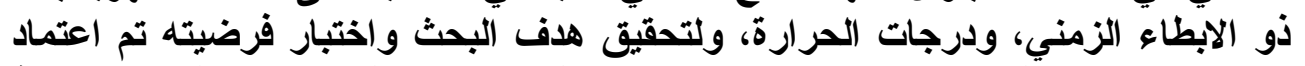

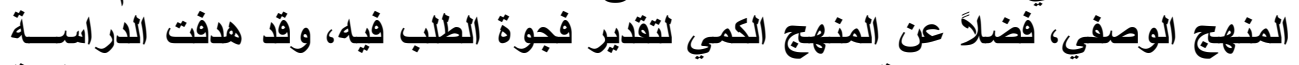

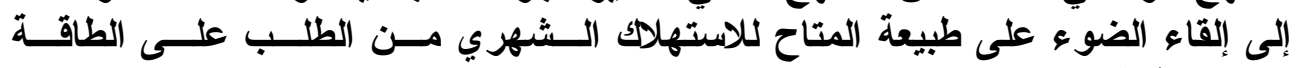

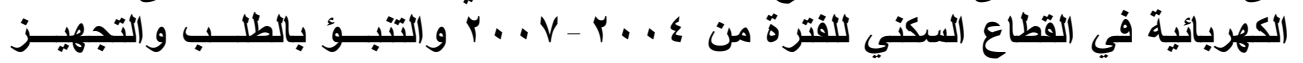

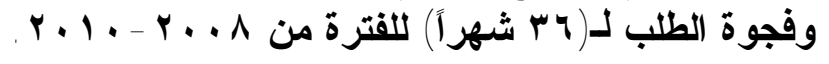

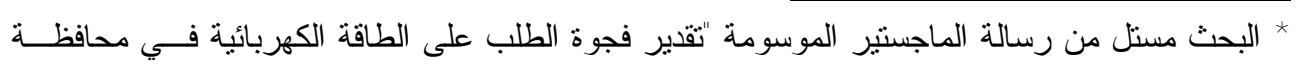

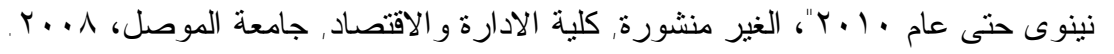

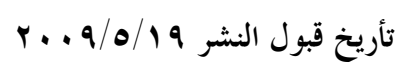

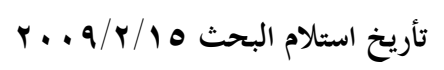




\title{
Estimating the Gap of the Electrical Energy Demand of Ninavah Governorate Residential Sector Until Year 2010
}

\author{
Anmar A. Al-Barwari (PhD) \\ Assistant Professor \\ Department of Economics \\ University of Mosul
}

\author{
Yosra H. Al-Hayali \\ Assistant Lecturer \\ Department of Economics \\ University of Mosul
}

\begin{abstract}
Electric energy ${ }^{1}$ is of vital importance for daily life activity of the modern societies, and its average individual consumption is one of the most important indicators of economic development. Residential sector of Nineveh Province has suffered since 1991 like all Iraqi Provinces from the lack of electricity supply. This was a setback in the way of growth and development. Therefore data collected of the monthly electrical energy sells of Nineveh residential sector for the period from 2004-2007. They were examined and discussed by Macklarn method: which disregards unusual values and be replaced with the average value of similar months in the data sample. As a hypothesis in this research, there are many variable factors shared by different ratios in the growth of the gap of electrical energy demand that are GDP and temperature. To achieve and test this hypothesis, the descriptive and quantitive approaches have been used in forecasting the gap of electrical energy demand. The goal of this study is to explore the nature of available monthly demanded electricity consumption in residential sector for the period 2004-2007 and forecasting Demand, Supply and its gap from 2008 to 2010.

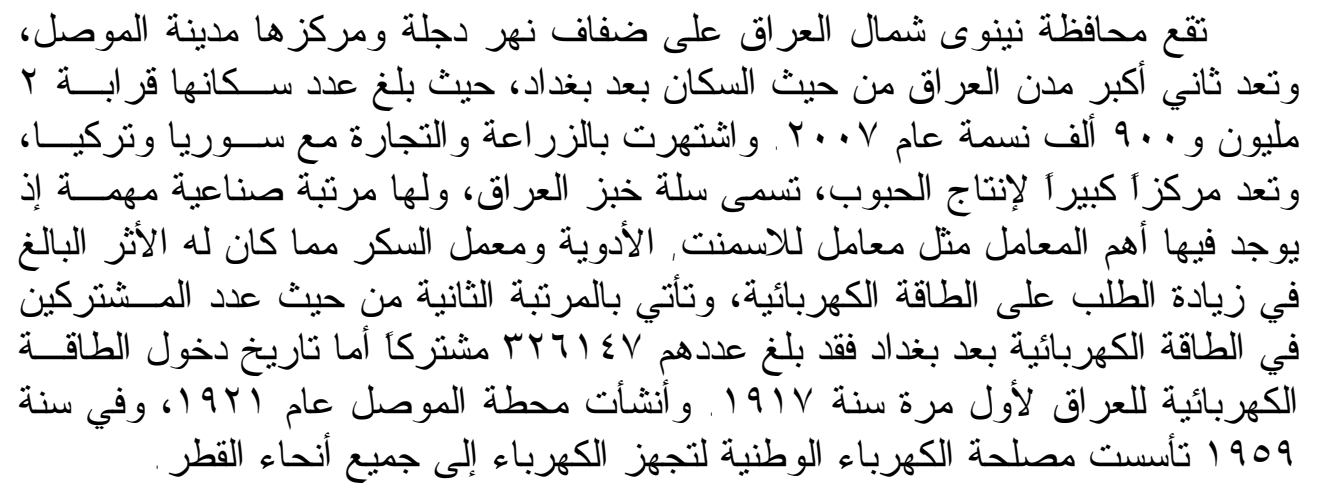

${ }^{1}$ The research has been quoted from a Master thesis by Yosra H. Al-Hayali (2008) University of Mosul. 


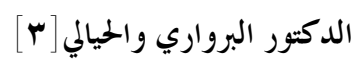

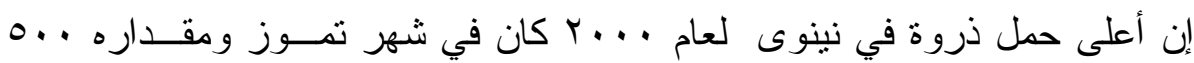

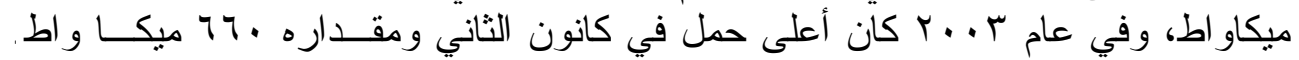

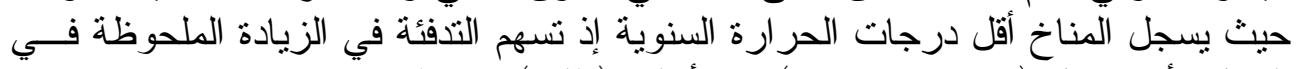

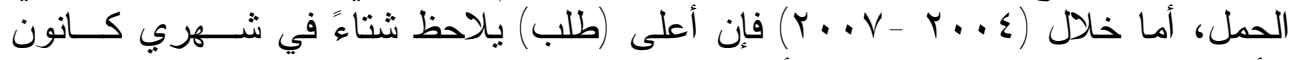

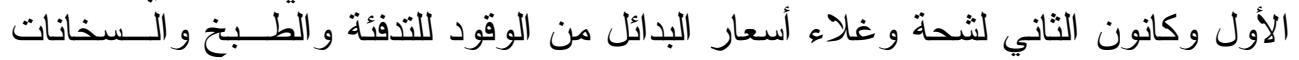

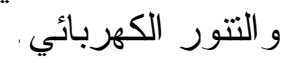

إن لتقدير فجوة الطلب على الطاقة الكهربائية للقطاع السكني لهحافظة نينوى أهمية

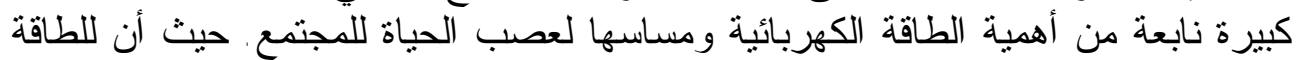

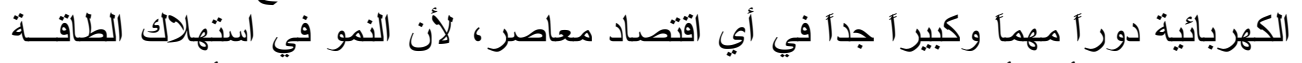

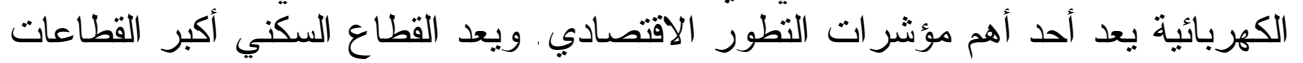
الاقتصادية في إستهلاكك الطاقة الكهربائية.

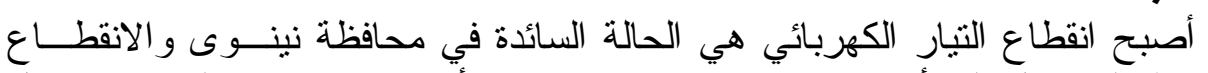
مشكلة البحث

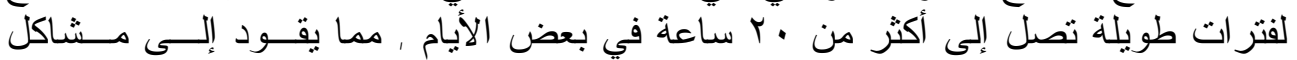

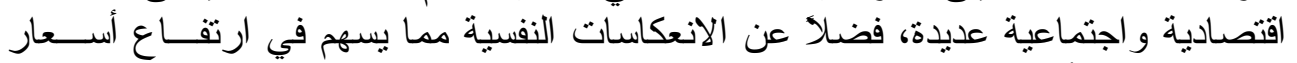

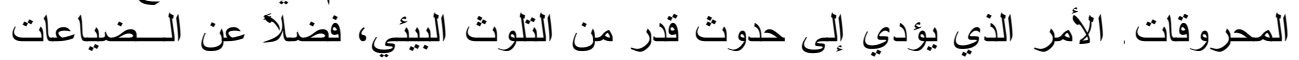

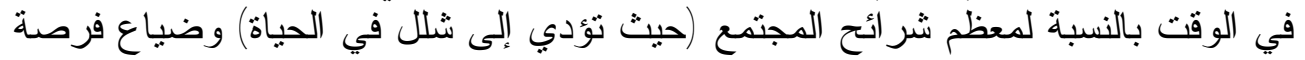

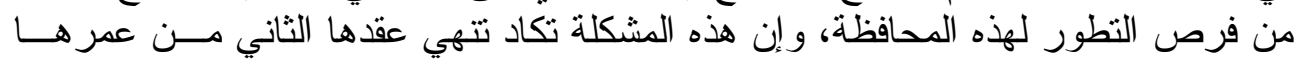
وهو زمن طويل نسبيا، و لاز الت مستمرة.

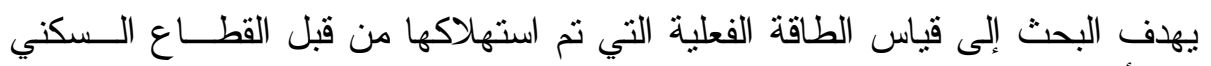

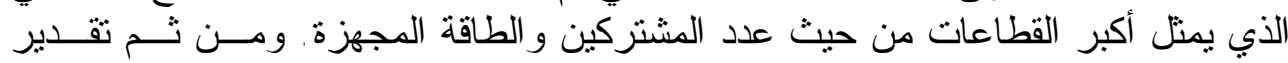

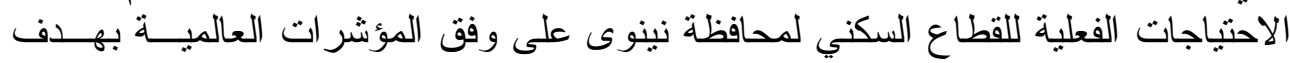

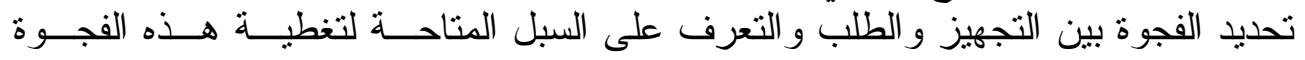
مستعينين بآخر المستجدات في مجالات الطاقة الكهربائية ومن ثم تقدير فجوة الطلب .

يفترض البحث أن أزمة نقص الطاقة الكهربائية في محافظة نينوى سبيها العديد من فرضية البحث

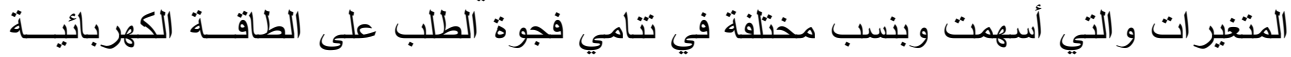

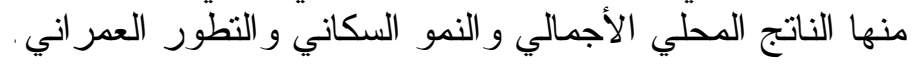

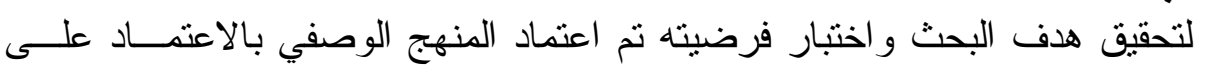

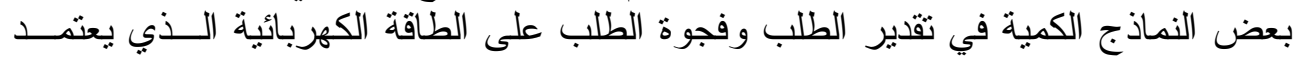
المقارنات الزمنية. 
إلاطار النظري و المفاهيمي

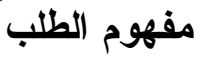

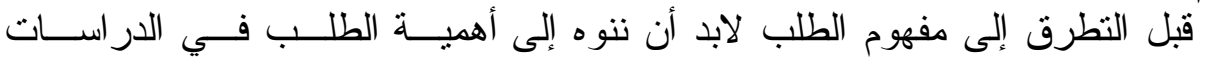

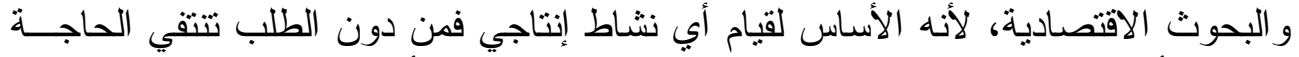

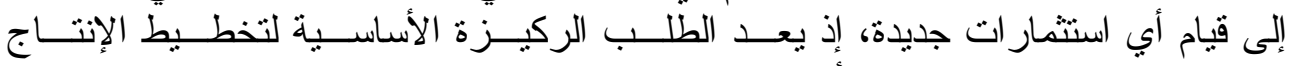

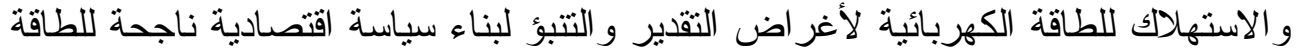

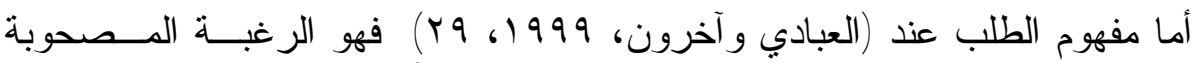

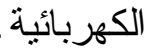

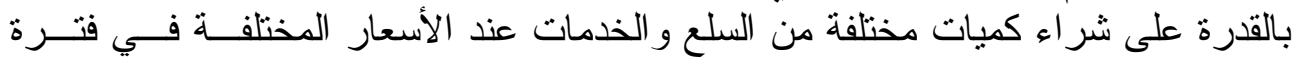
أما العوامل المؤثرة في الكمية المطلوبة من أي سلعة (ســعيد وحسسين، ع . . Y، زمنية معينة. $:(\wedge r$

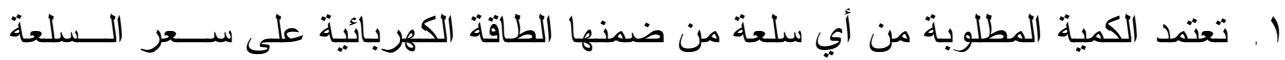

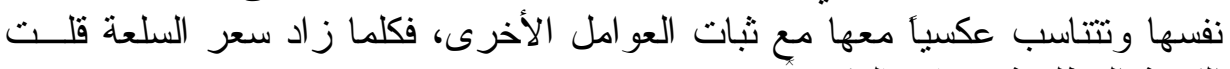

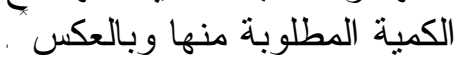

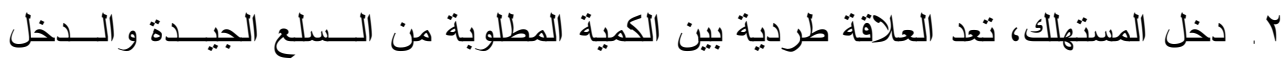

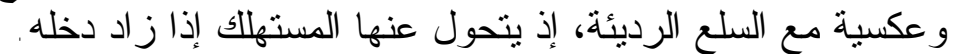

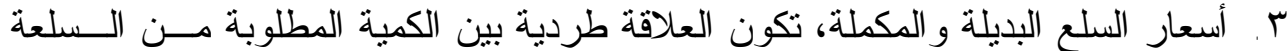

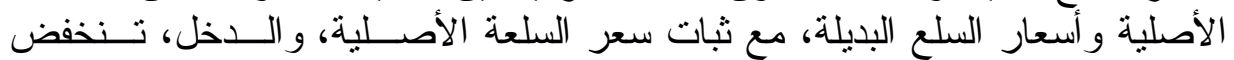

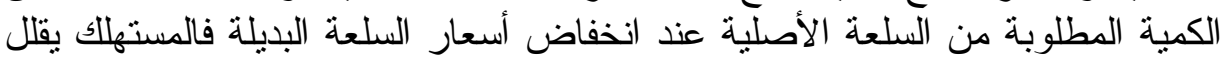

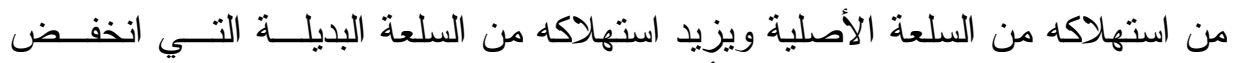

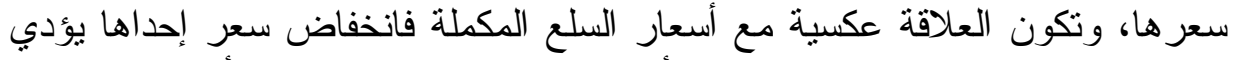

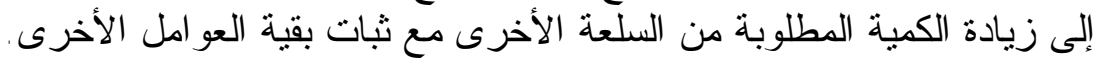

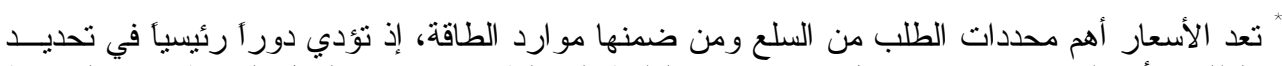

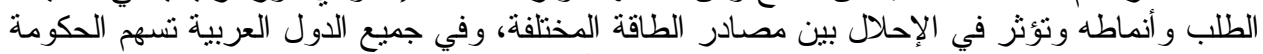

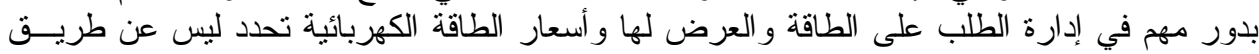

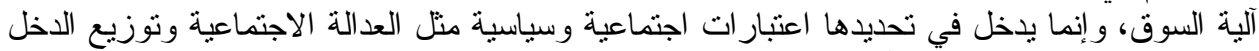

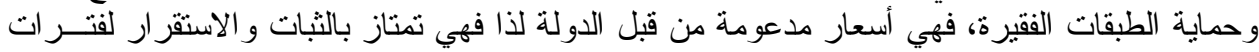
طويلة.

هنالك ثلاثة اعتبار ات مهمة لتحديد أسعار الطاقة الكهربائية:

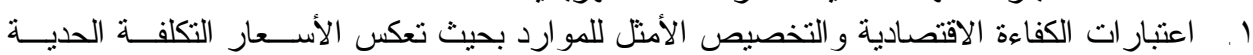

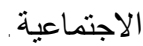
r. ـ العدالة الاجتماعية من خلال تقديم الدعم لحماية الطبقات الضعيفة في المجتمع أو لتحفيز النـشاط

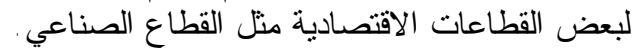

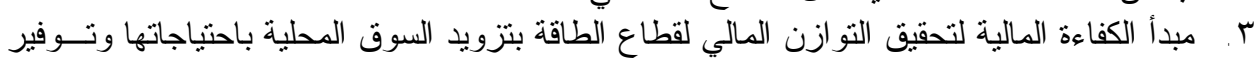

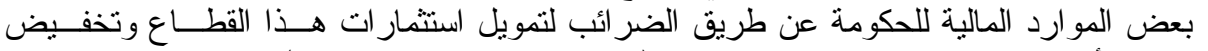

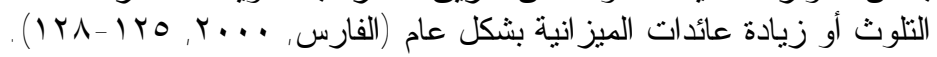




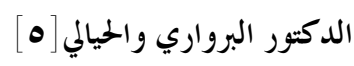

ع. . ذوق المستهلك، تكون العلاقة طردية بين الكمية المطلوبة وذوق المستهلاك, فإذا كسـان

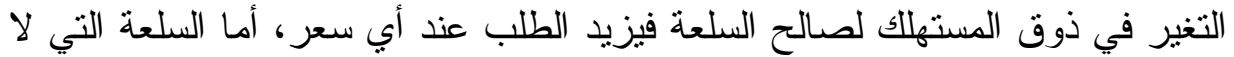

تلائم ذوق المستهلك فيتحول عنها أي يقل الطلب عليها فيكان فيكون علاقة عكسية.

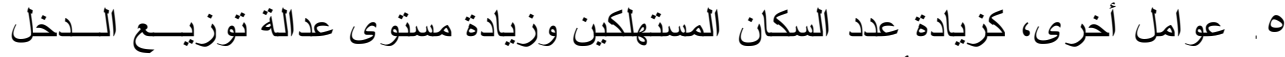

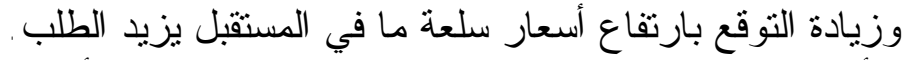

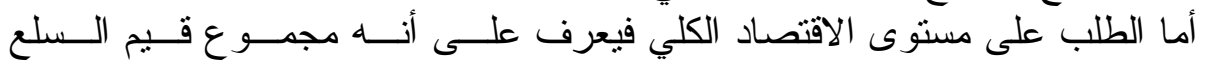

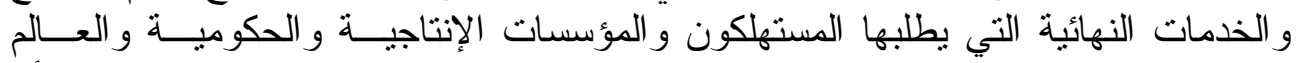

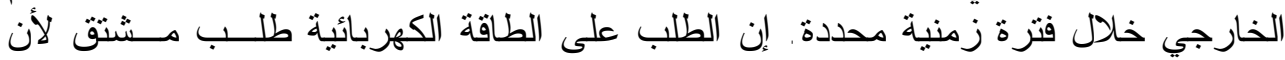

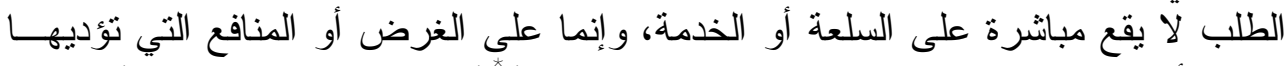
السلعة أو الخدمة مثل التذفئة و التبريد و الطهي و غير ها) (William, 1977, 240).

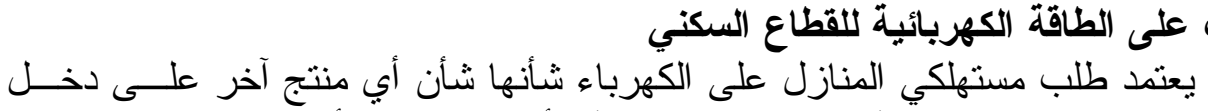

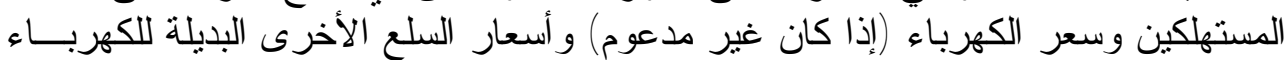

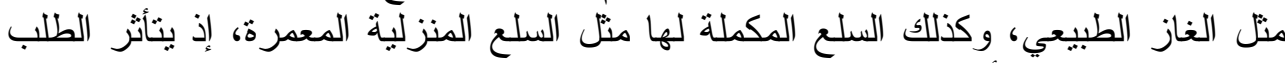

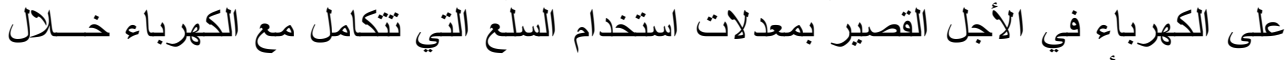

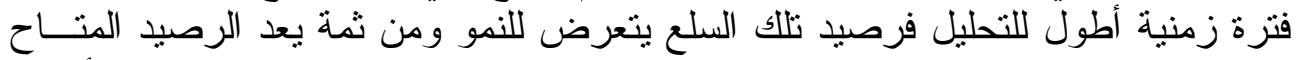

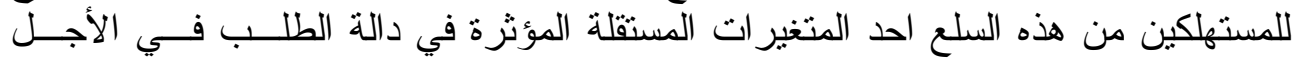
الطويل.

وكنلك درجات الحر ارة خلال فترات معينة من السنة تؤثر في الطلب على الطاقـــة الكهربائية, ومتوسط عدد أفر اد الأسرة وفيما يأتي شرح موجز لكل من منها:

\section{محدات الطلب على الطاقة الكهربائية للقطاع السكني:}

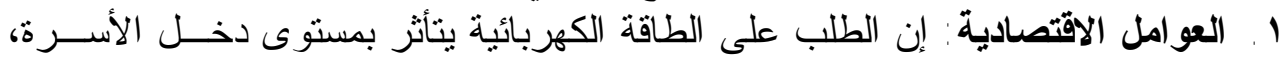

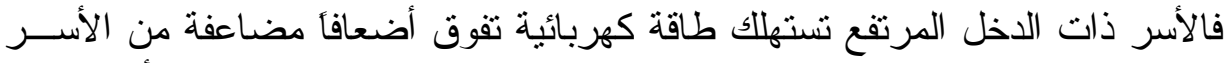

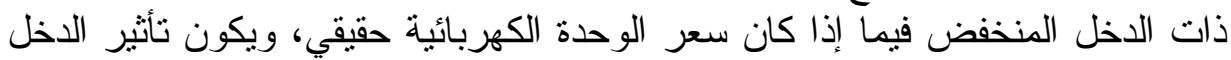

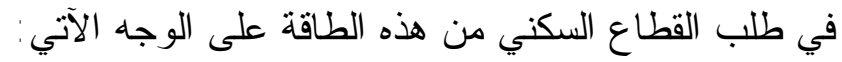

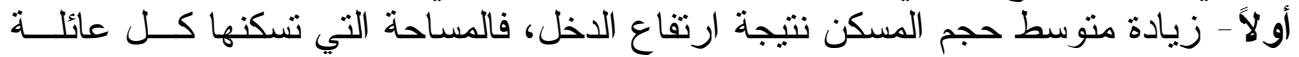

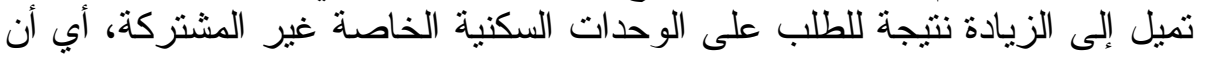

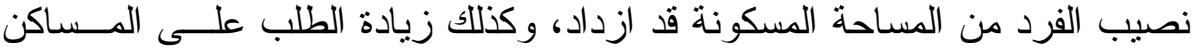

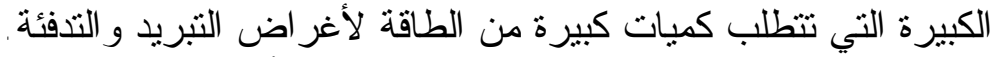

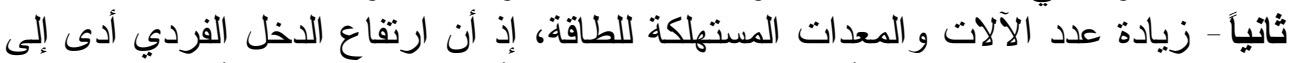

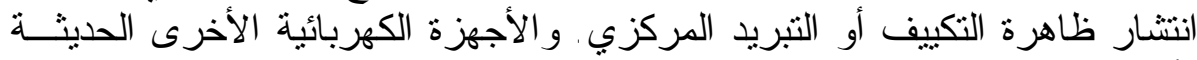

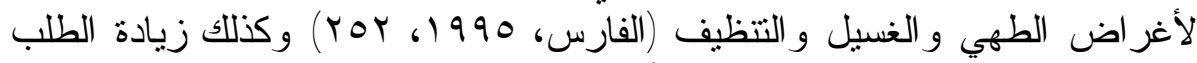
على الخدمات المستهلكة للطاقة بشكل أكبر مثل الآلات.

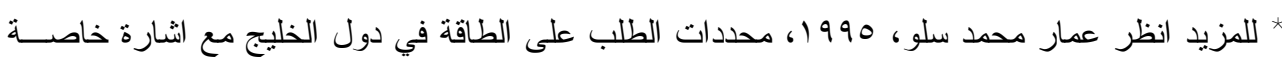

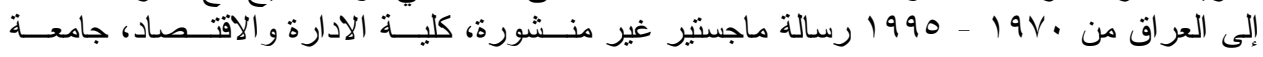

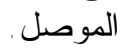




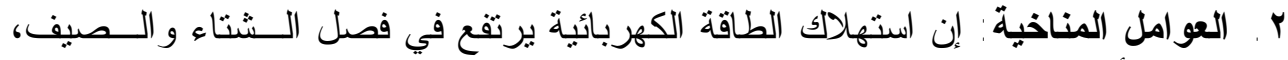

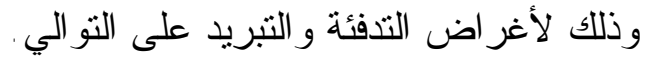

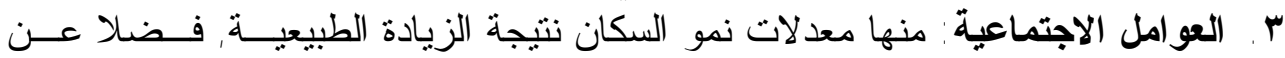

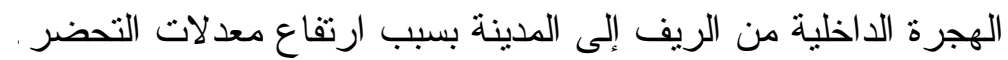

إن الطلب على الطاقة الكهربائية محط إهتمام العديد من الدراسات في الدول النامية

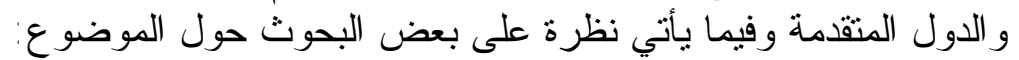

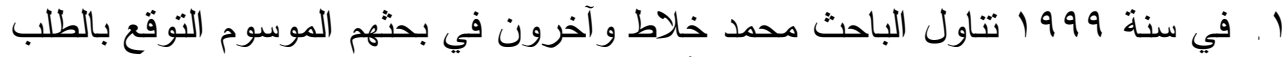

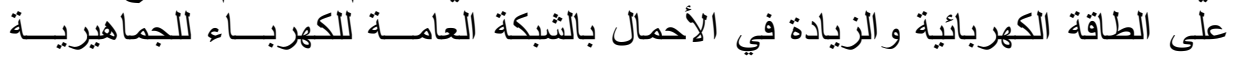

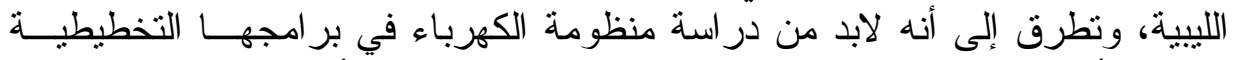

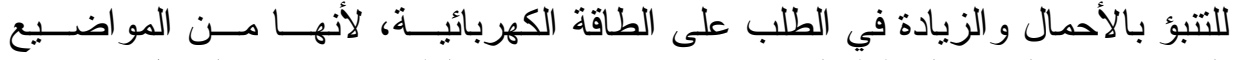

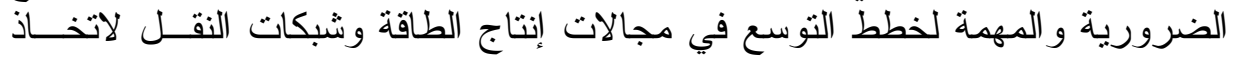

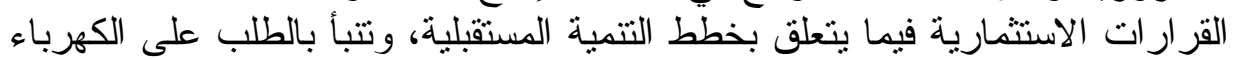

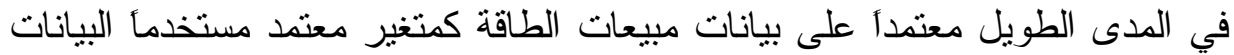

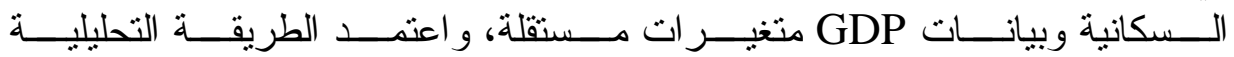
.ANALYTICAL-METHOD

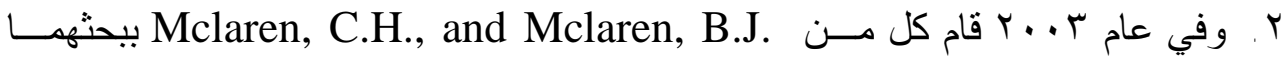

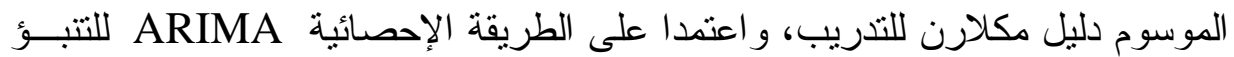

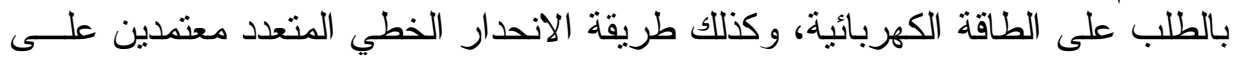

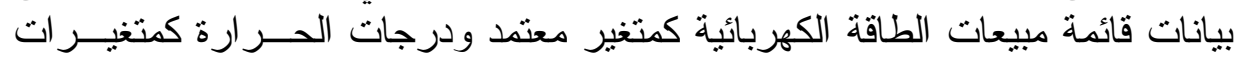

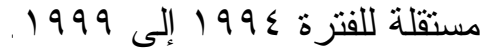

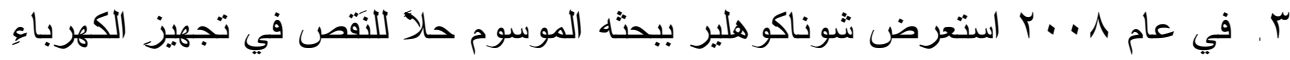

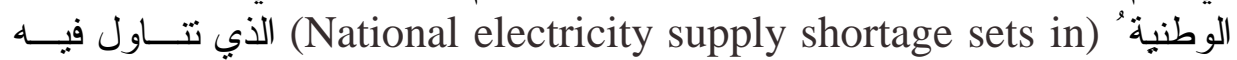

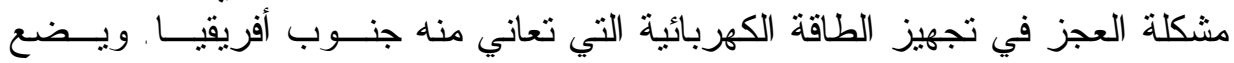

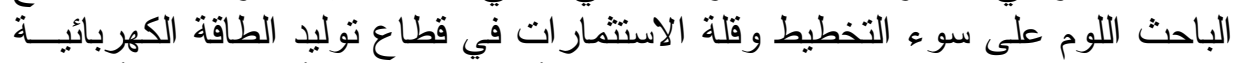

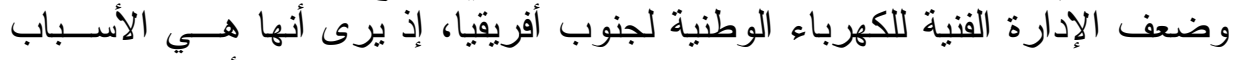

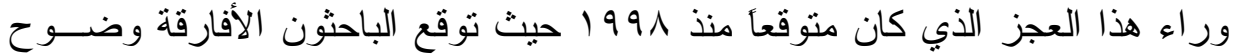

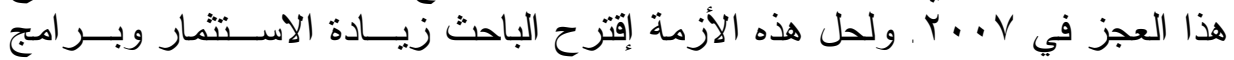

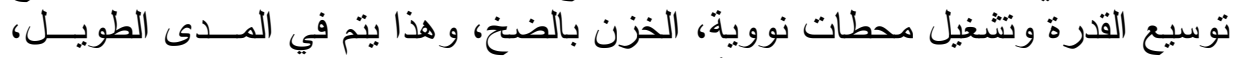

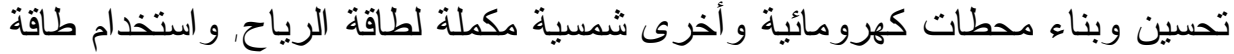

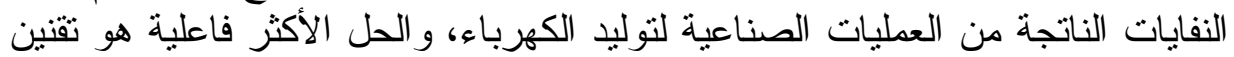
استخدام الطاقة الكهربائية. وفي هذا البحث وجد أن العلاقة طردية بين GDP و والطلب على الطاقة الطئة الكهربائية،

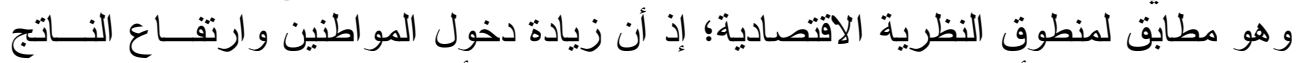

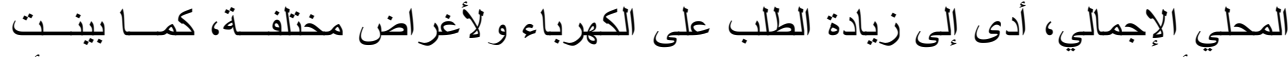

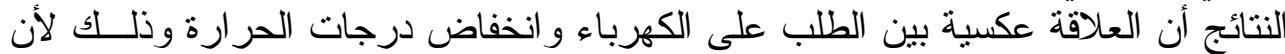

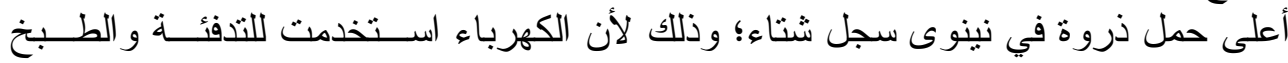




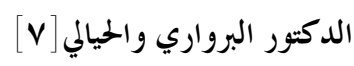

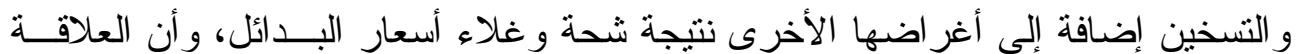

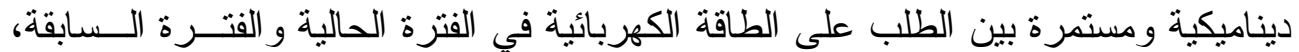
وقد تم استخدام بيانات شهرية لكل من المتغير ات المفسرة و المستجيبة.

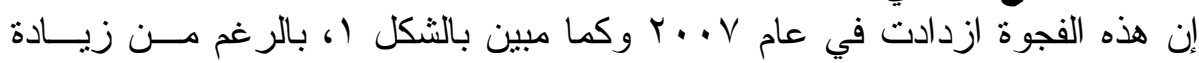

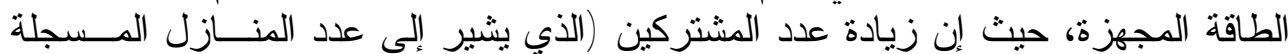

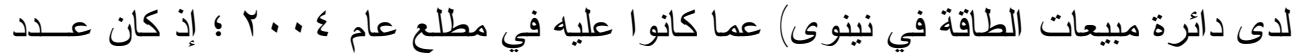

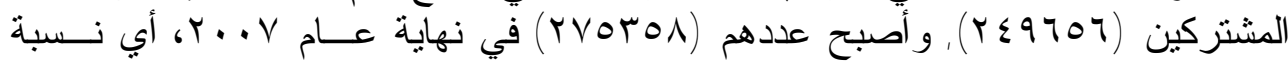

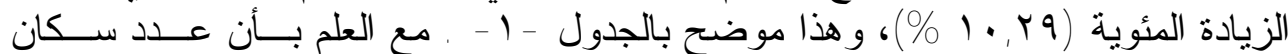

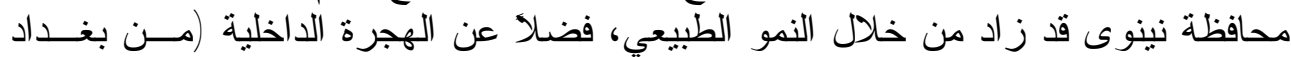

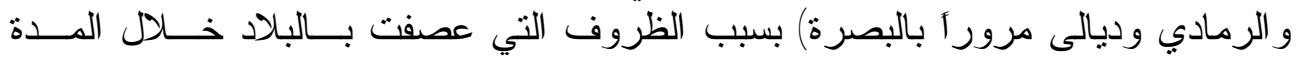

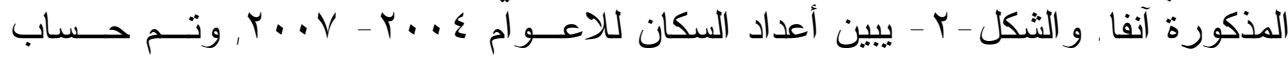

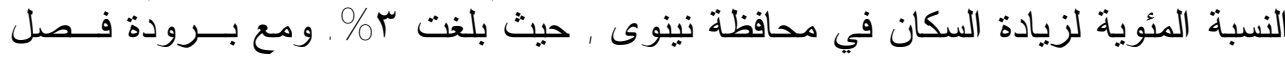

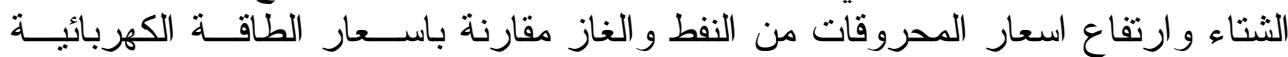

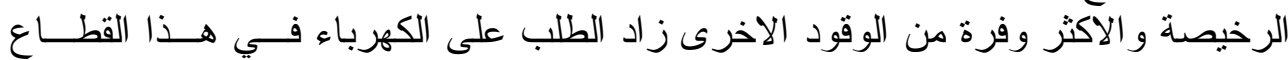

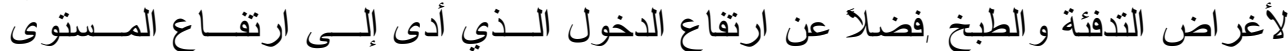

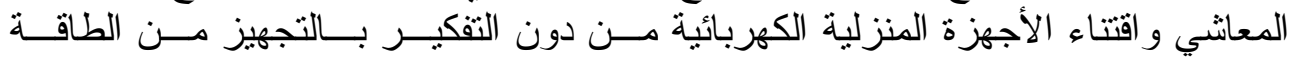
الكهربائية.

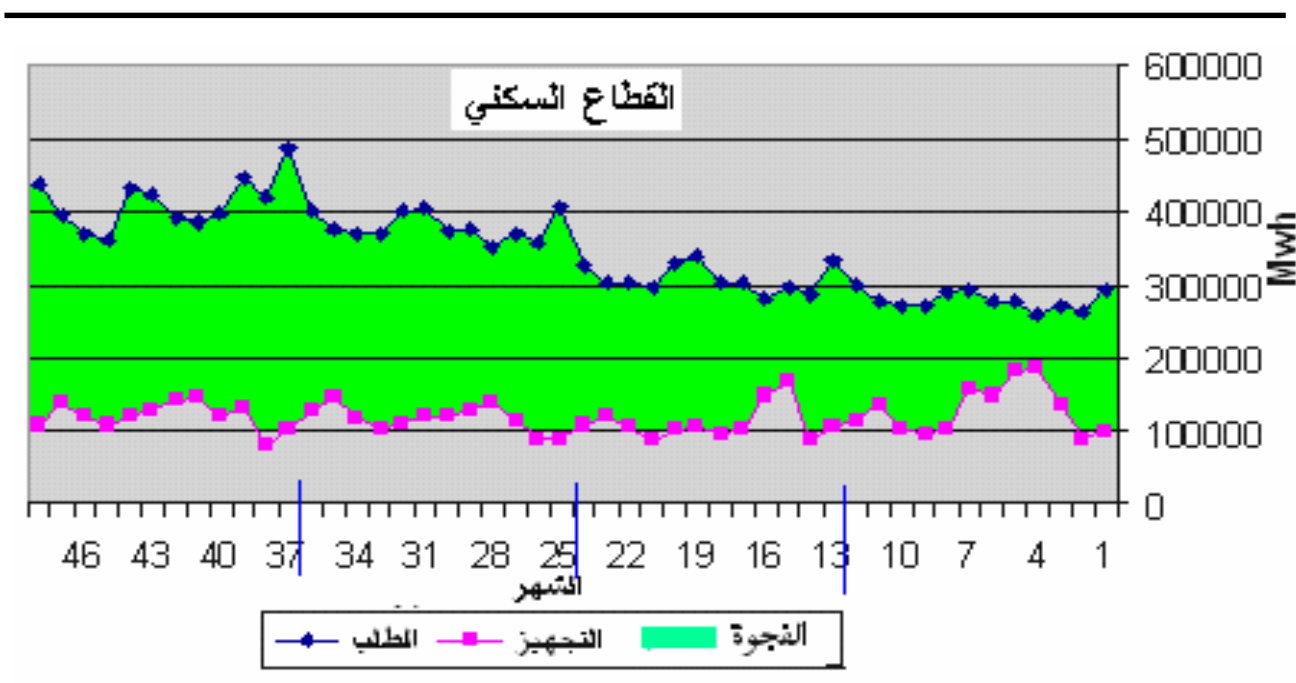

| (الثكل 1

الطاقة الكهربائية المطلوبة والمجهزة والفجوة للقطاع السكني

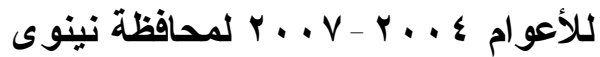

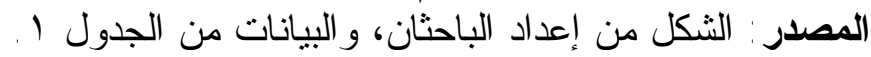




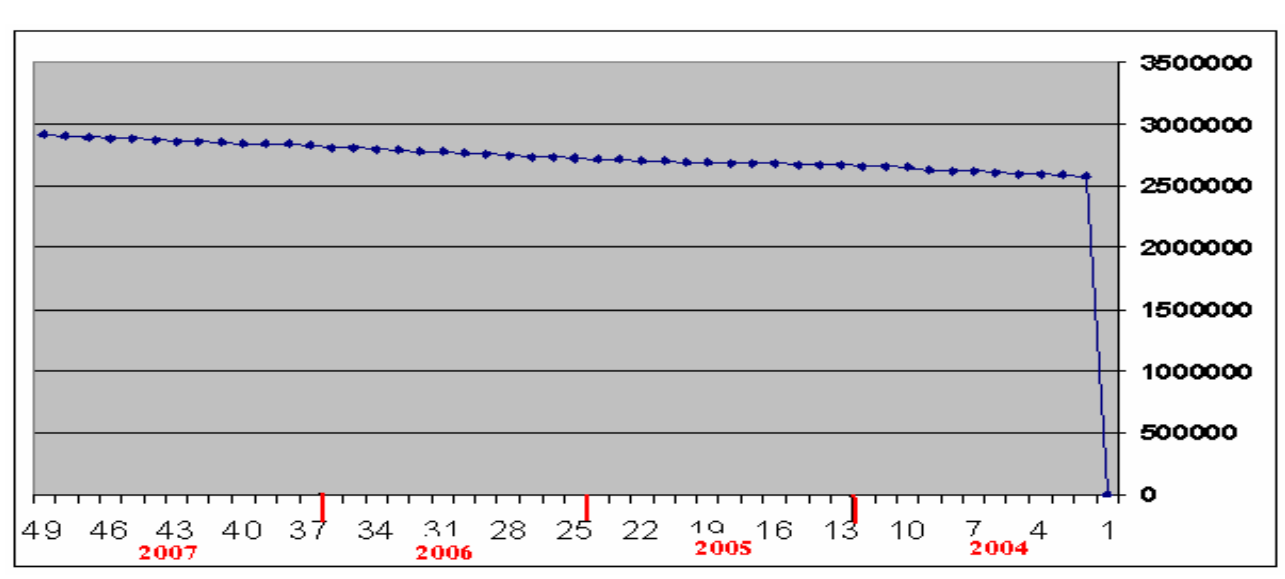

$$
\text { الشكل الشوى }
$$

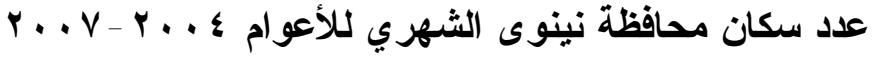

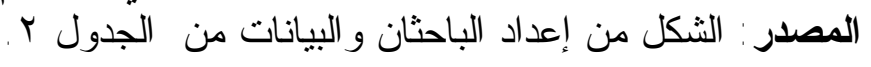

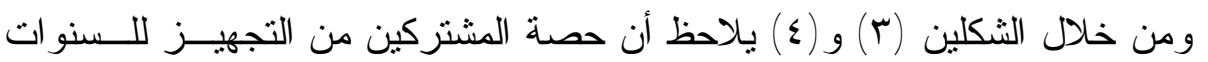

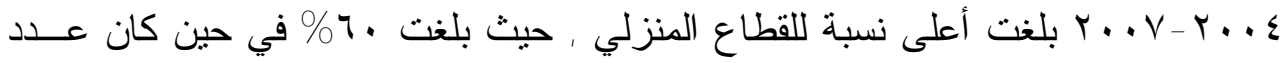

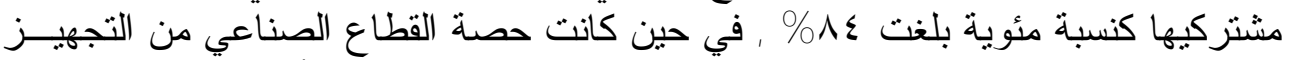

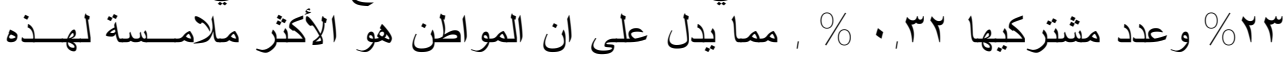

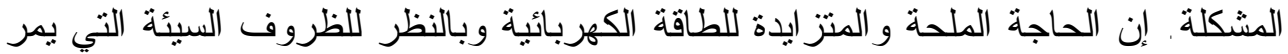

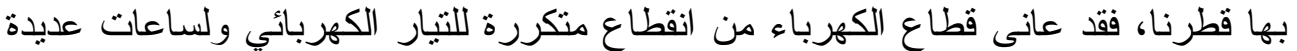

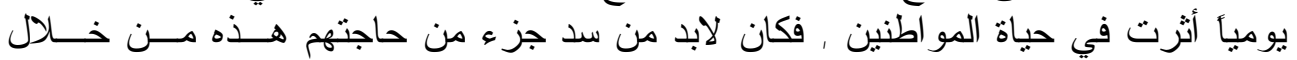

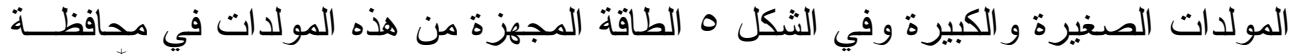

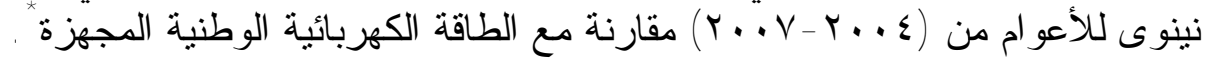

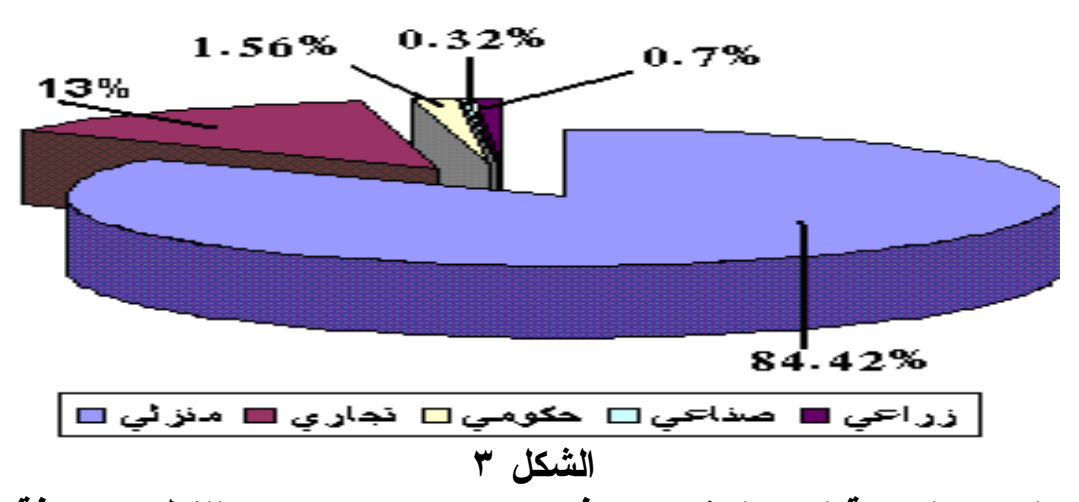

النسب المئوية لعدد المشتركين في توزيع كهرباء نينوى للقطاعات كافة

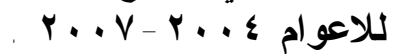

المصدر: الحيالي , 1... ب, 09.

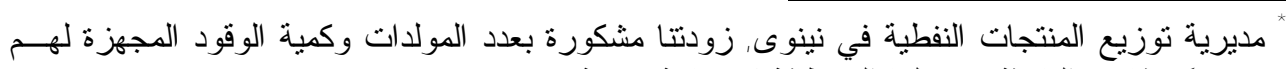
شهرياً, وقامت الباحثة بتحويلها إلى طاقة كهربائية منتجة. 


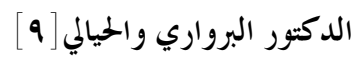

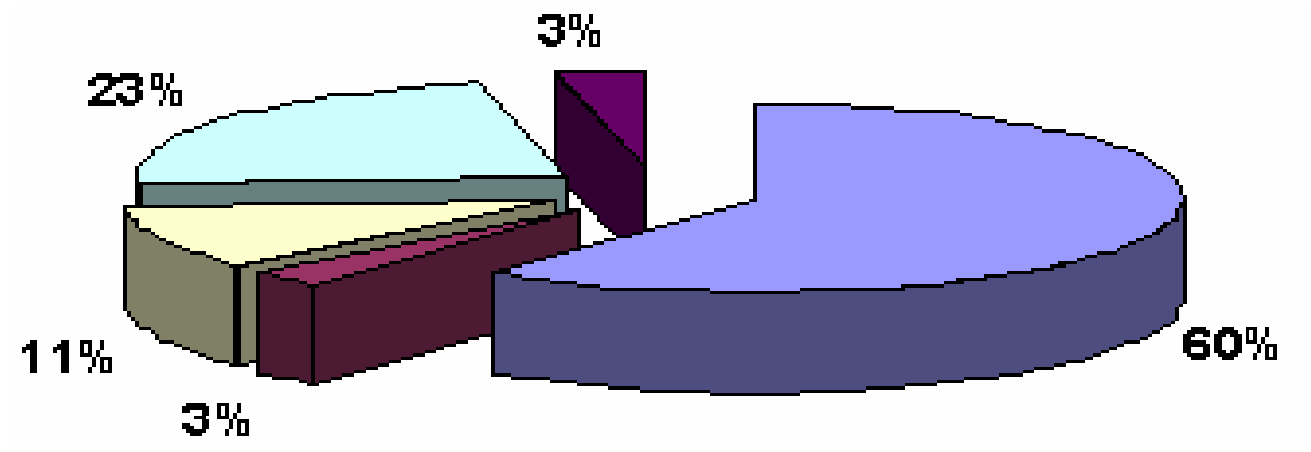

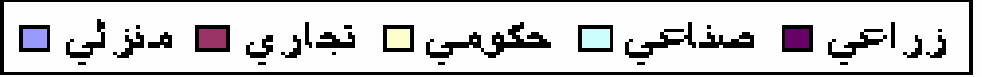

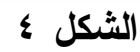

النسب المئوية لحصص المشتركين من التجهيز في توزيع كهرباء نينوى للقطاعات كافة

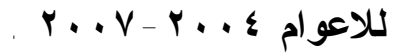

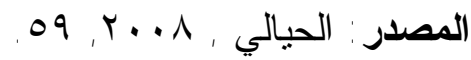

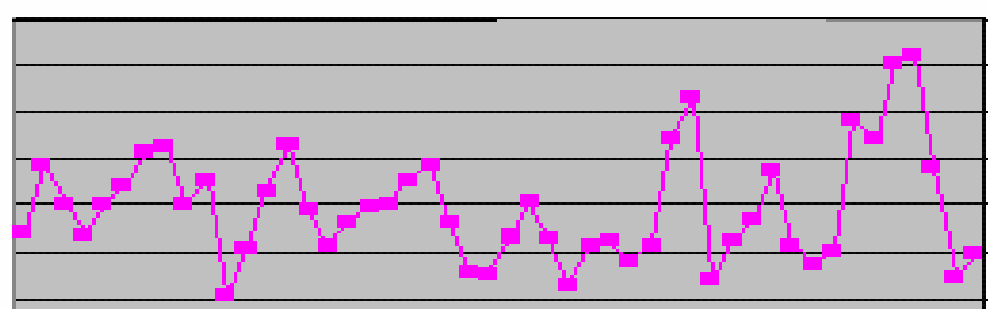

200000

180000

160000

140000

120000

100000

80000

60000

40000

20000

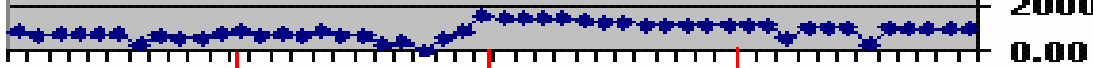

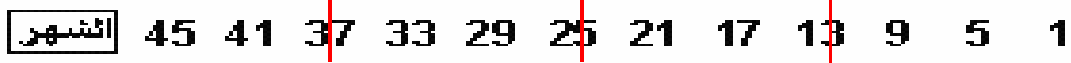

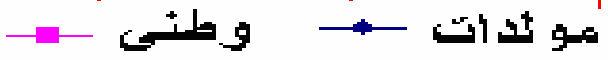

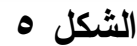

الطاقة الكهربائية المجزة Mwh شهرياً من الكهرباء الوطنية مقارنة بالطاقة المنتجة

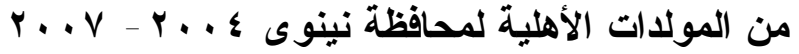

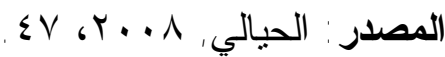

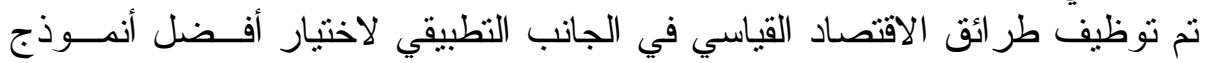

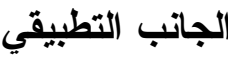

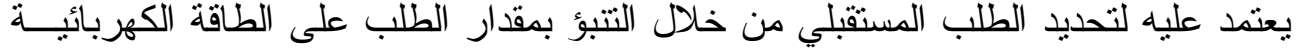

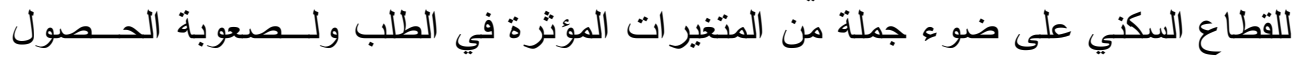

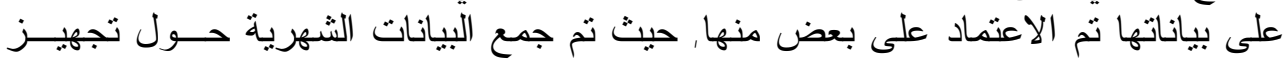


الطاقة الكهربائية (مبيعات الطاقة) للفترة من كانون الثاني لعام ع . . ب ولغاية كانون الأول

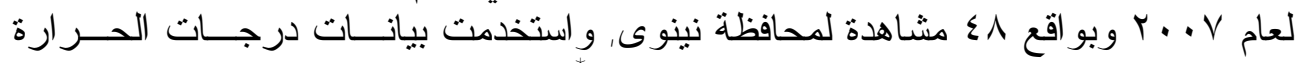

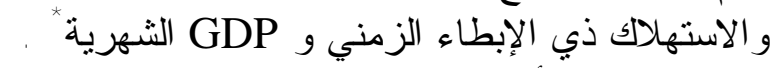

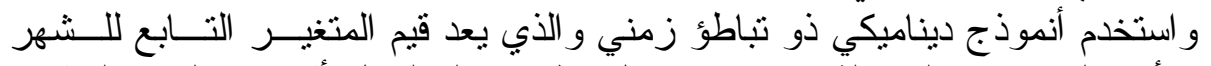

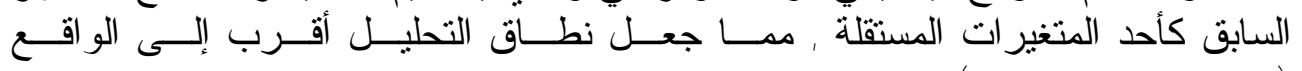

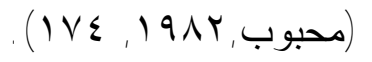

تقدير الطلب على الطاقة الكهربائية في القطاع المنزلي : : تشير نتائج تقدير الطلب علــى الطي

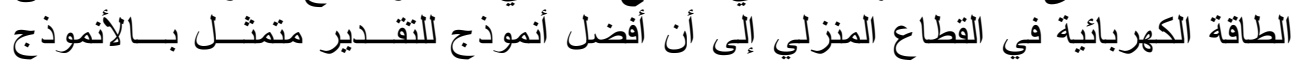
الخطي: الخط:

QdY1T $=-414+0.482$ Qd1t-1 -0.894 Temp +1.66 GDP

(1)

$$
\begin{aligned}
& \begin{array}{lllll}
Z & -3.18 & 3.91 & -2.06 & 3.79
\end{array} \\
& \mathrm{R}-\mathrm{Sq}=87.0 \% \quad \mathrm{R}-\mathrm{Sq}(\mathrm{adj})=86.1 \% \quad \mathrm{~F}=98.20 \\
& \text { D.W }=1.45 \quad \mathrm{~h}=3.7
\end{aligned}
$$

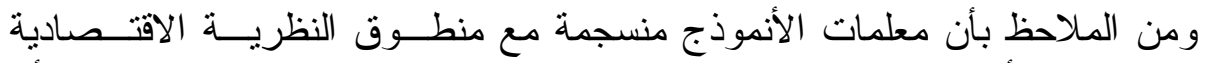

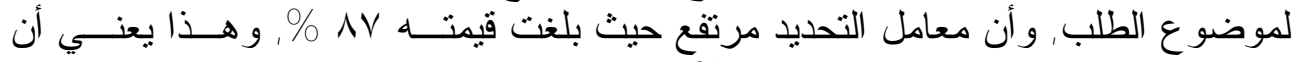

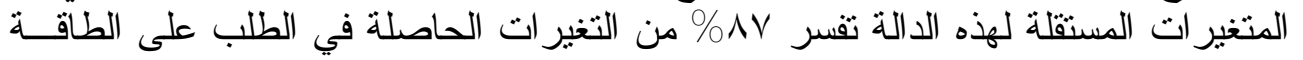

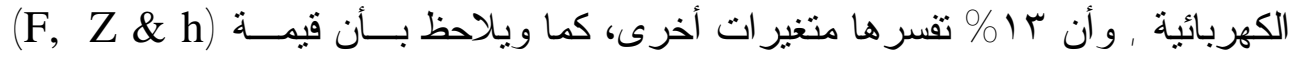

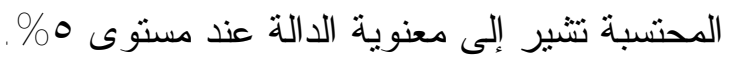

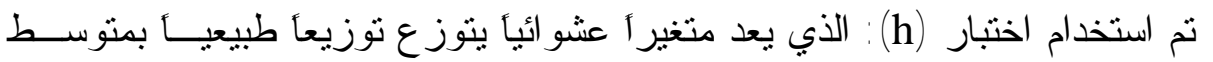

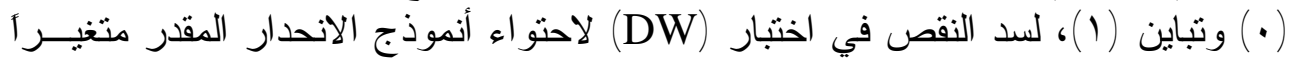

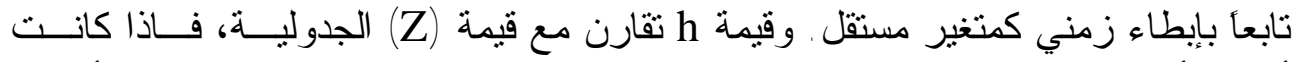

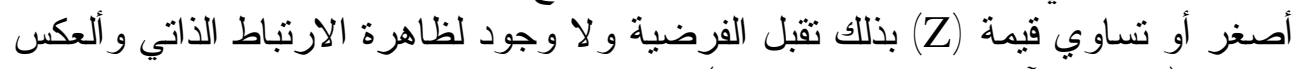

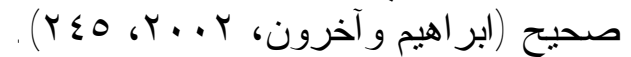

$$
\begin{aligned}
& h=\hat{p} \sqrt{\frac{n}{1-n\left\{V\left(\hat{\beta_{1}}\right)\right\}}}
\end{aligned}
$$

* تم حساب الـ GDP الثهرية لمحافظة نينوى وذلك من البيانات الإحصائية السنوية لمنظمة الامم المتحدة

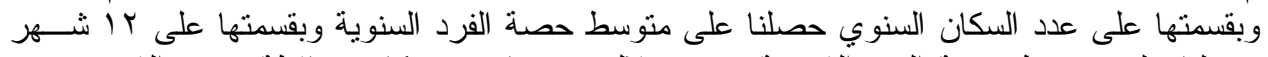

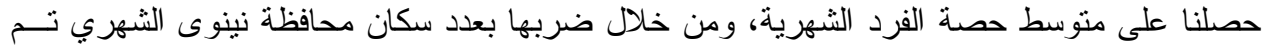

${ }^{*}$ QdY1T = - 852 + 0.492 Qd1t-1 - 0.977 Temp + 0.00440 Cons1 -0.000237 Qs الثهرية. -0.00000013 GenFuel - 0.00107 Mwh_DieslGen

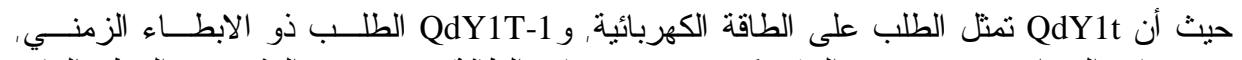

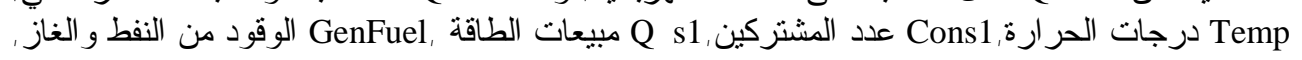
Dies1Gen 


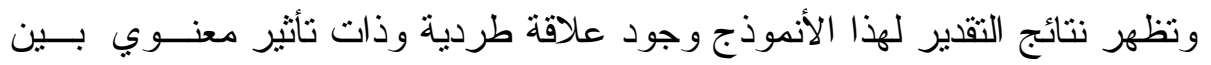

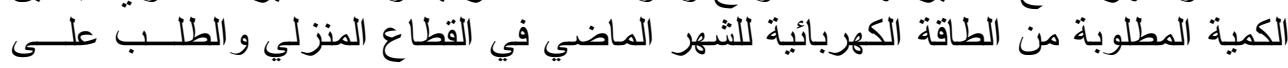

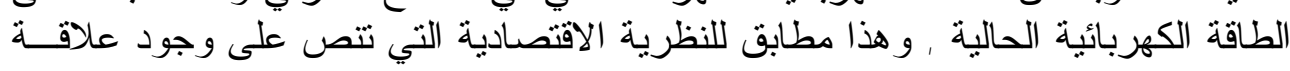

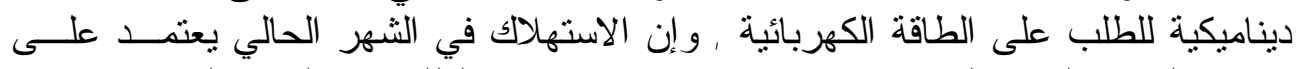

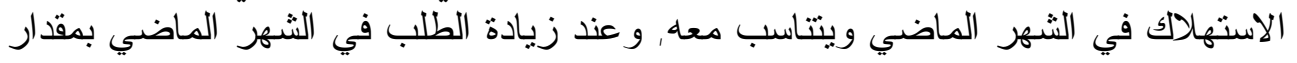

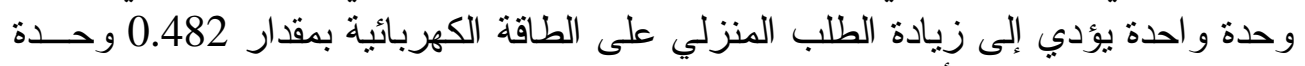

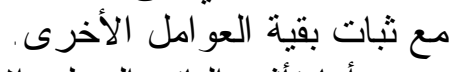

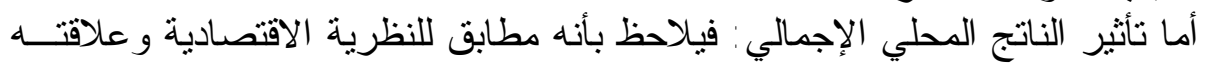

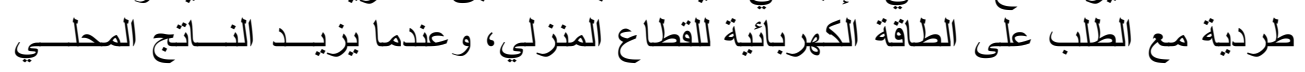

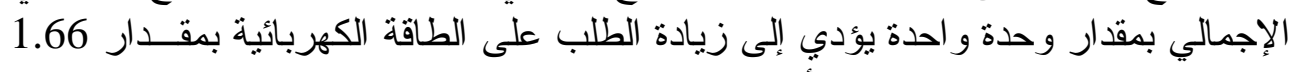

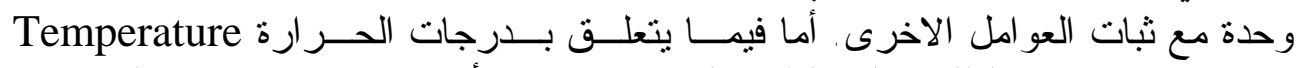

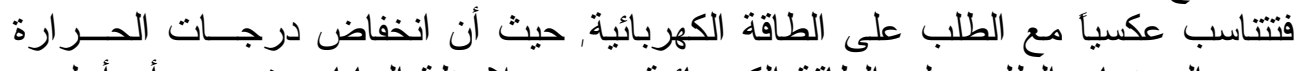

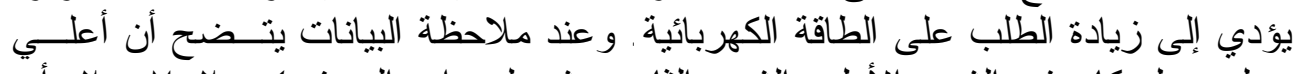

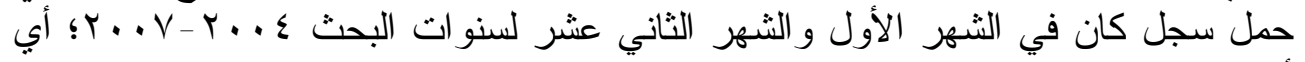

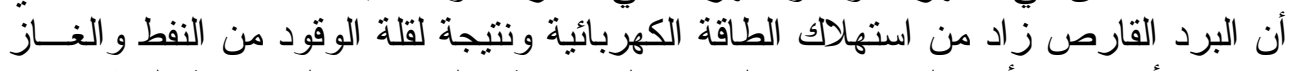

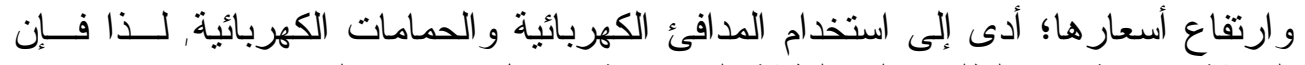

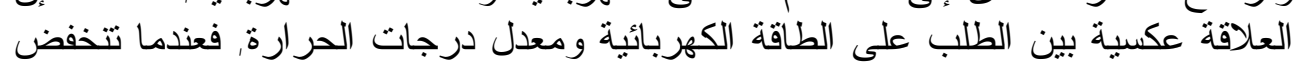
درجات الحر ارة درجة و احدة يرتفع الطلب على الطاقة الكهربائية بمقدار (0.894) وحدة.

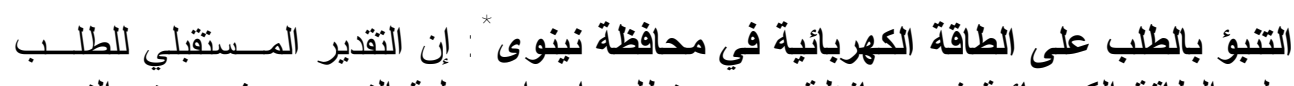

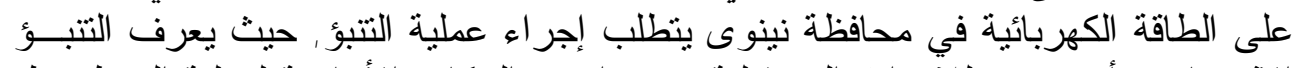

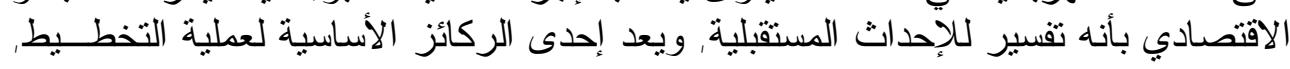

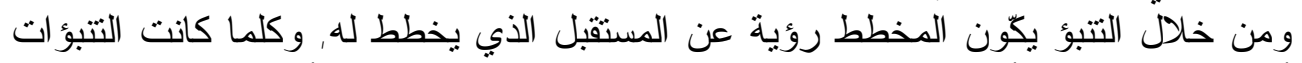

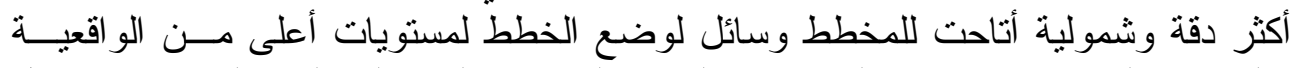

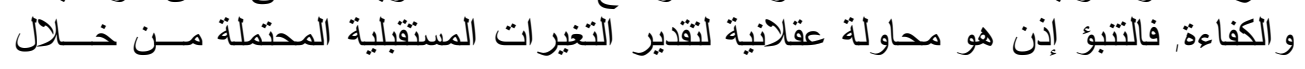

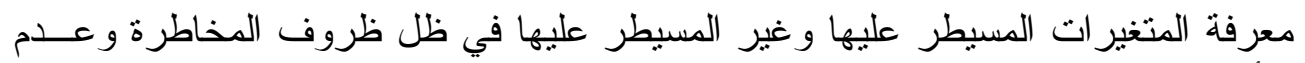

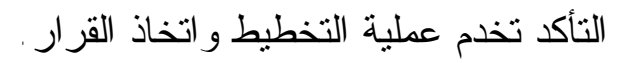
ويمكن استخذام التتبؤ الكمي عند توفر ثناثة شروط (سلو ، 990 19، بهو) .

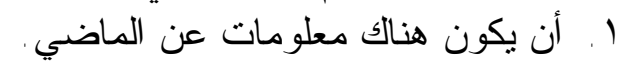

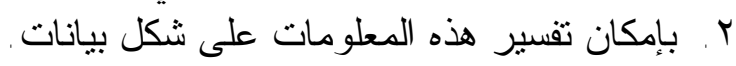

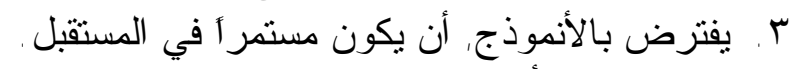

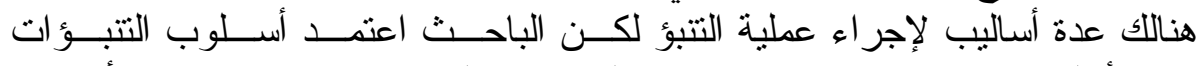

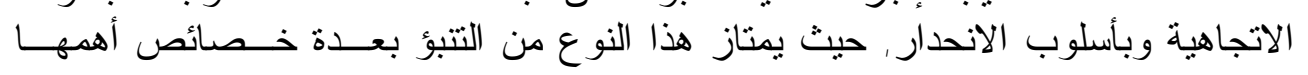

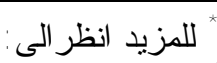
أ. توفيق عبد الرحيم يوسف، r...r، إدارة الأعمال التجارية الصغيرة، طا، دار صفاء للنشر والتوزيع،

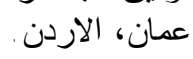

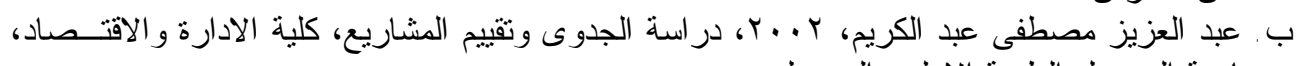

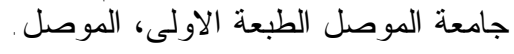


إمكانية خضو عه لاختبار ات الدقة الإحصائية وبعد أن ثم اختيار أفضل النمــاذج المقــدرة

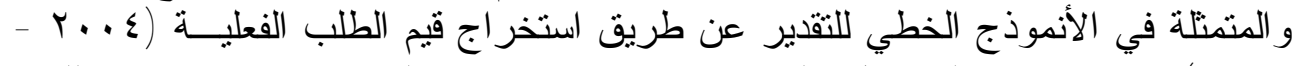

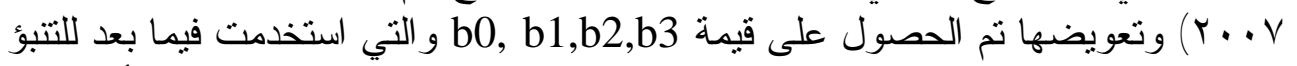

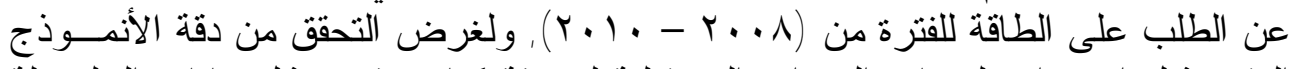

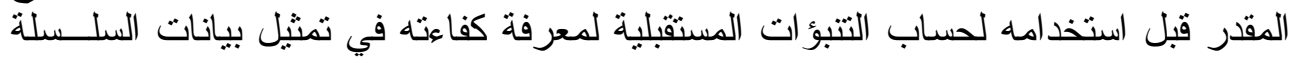
الزمنية استخدم معامل تباين ثايل .

Thiele's Inequality * (Makridakis, 1978 , 51) معـل تبـاين ثايـلـل Coefficient و هو من المعايير المستخدمة في تقيم الكفاءة التتبؤية للانموذج المقدر و الذي يتميـز بدقة التتبؤات من خلال المعادلة الآتية: $U=\sqrt{\frac{\sum_{i=1}^{n-1}\left(\frac{F_{i+1}-X_{i+1}}{X_{i}}\right)^{2}}{\sum_{i=1}^{n-1}\left(\frac{X_{i+1}-X_{i}}{X_{i}}\right)^{2}}}$

حيث أن : Uيمثل معامل تباين ثايل .

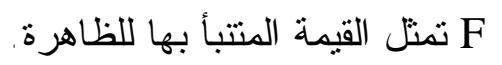
ت تمثل القيمة الحقبقية للظاهرة i+1 تمثل القيمة اللاحقة للظاهرة.

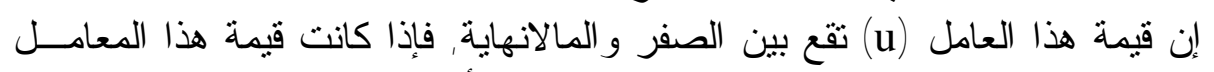

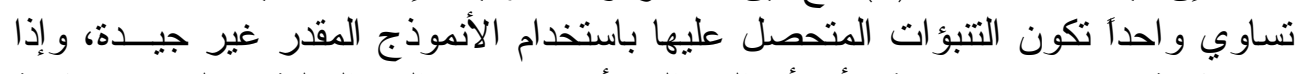

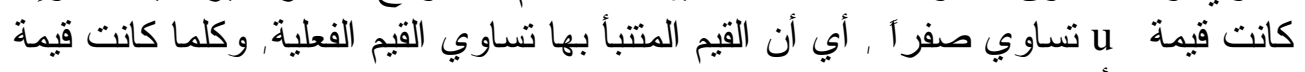

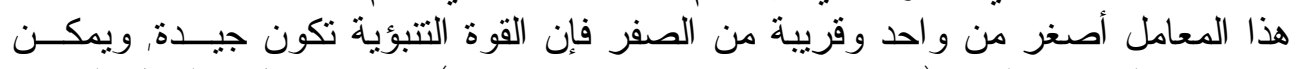

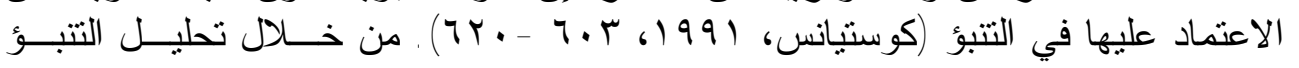

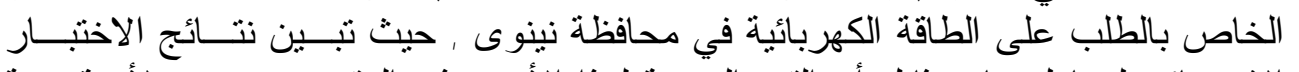

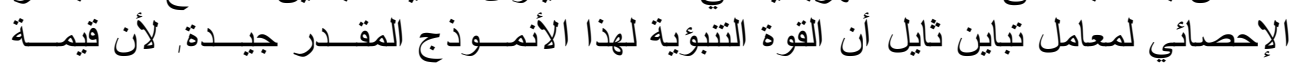

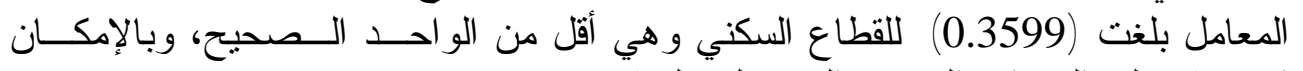
الاعتماد على التتبؤات التي يتم الحصول عليها للفيا.

التقدير المستقبلي لتجهيز الطاقة الكهربائية للقطاع السكني لمحافظة نينوى

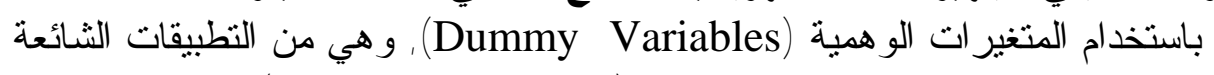

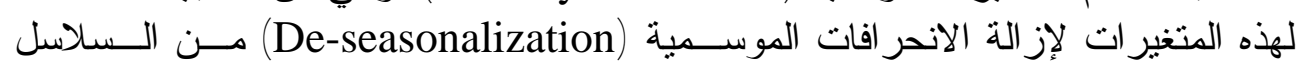




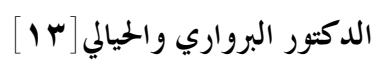

الزمنية. ينتين أن التعديلات الموسمية يتم تقدير ها وذلك بتــمينها (متغـــرات وهميــة) فصلية أو شهرية: حيث إن: (1,0) = Q1t

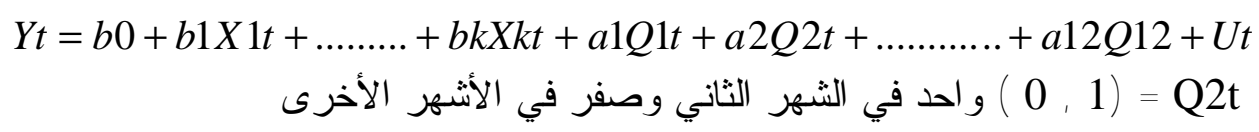

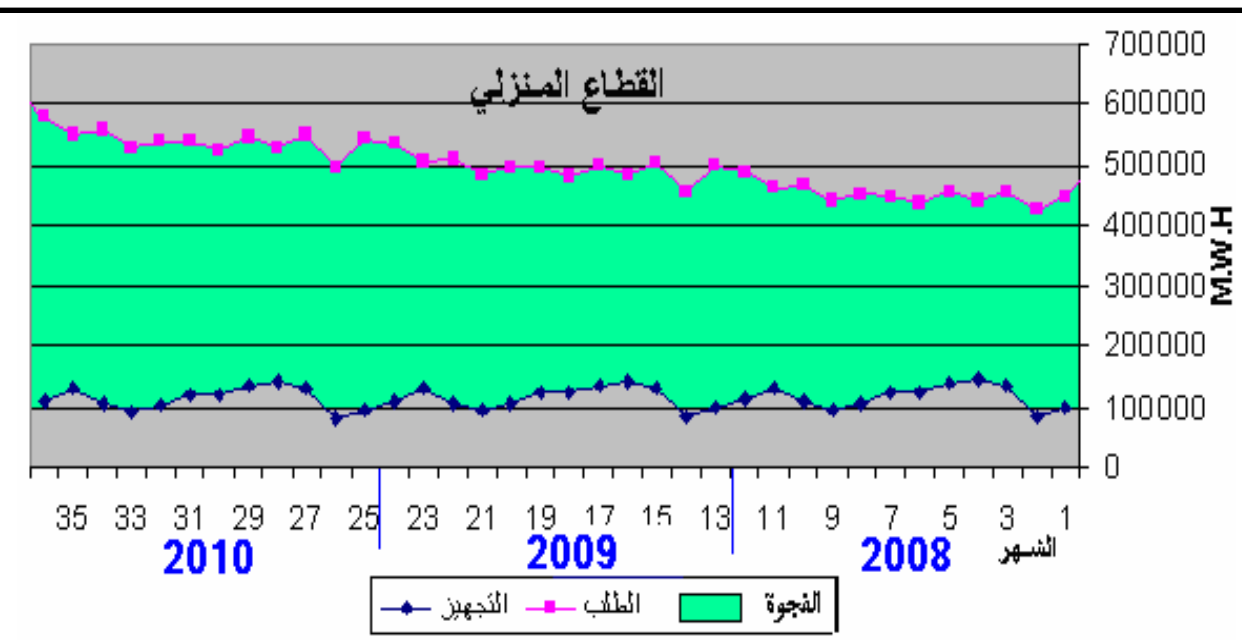

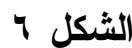

الطاقة الكهربائية المطلوبة والمجهزة والفجوة للقطاع المنزلي المتنبأ بها

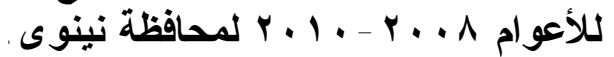

المصدر: الثكل من إعداد الباحثان بالاعتماد على بيانات الجدولين او بـ.

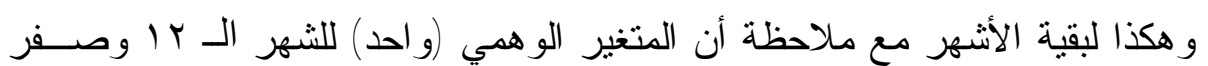

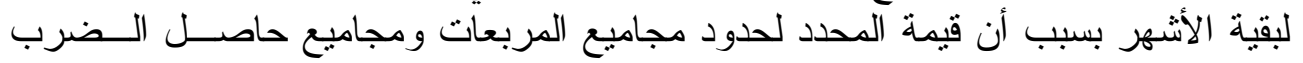

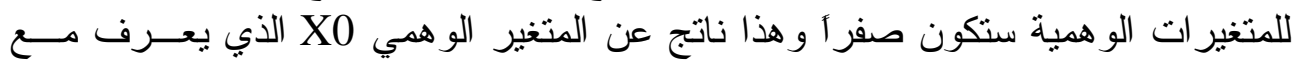

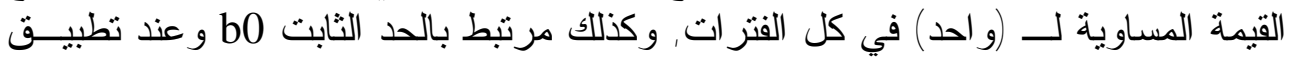

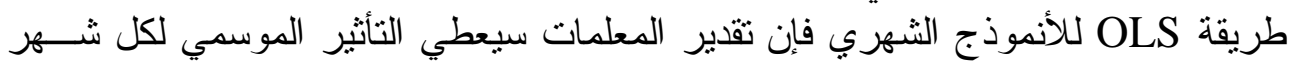

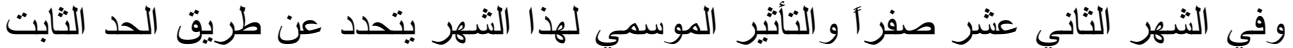

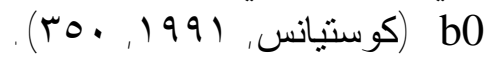
إن أفضل أنموذج لتقدير التجهيز على الطاقة الكهربائية في القطاع الـسكني كــان

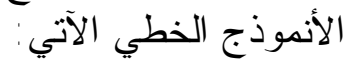

$$
\begin{aligned}
\text { Qs1 } & =118-0.104 \text { Obs_No }-14.4 \mathrm{Jan}-28.8 \mathrm{Feb}+21.4 \mathrm{Mar} \\
& +32.3 \mathrm{Apr}+24.7 \mathrm{May}+11.5 \mathrm{Jun}+12.1 \mathrm{Jul}-6.3 \mathrm{Aug}
\end{aligned}
$$




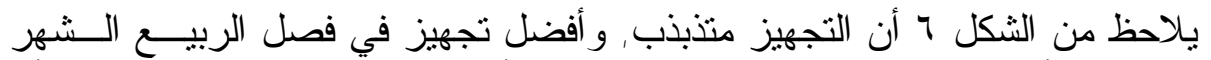

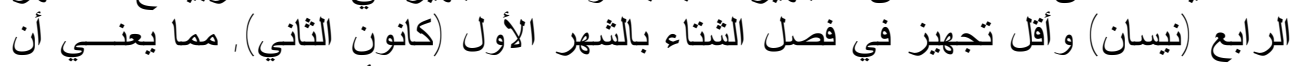

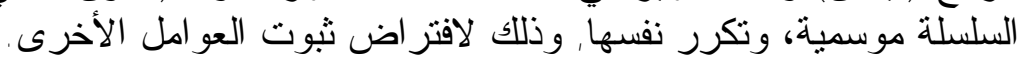

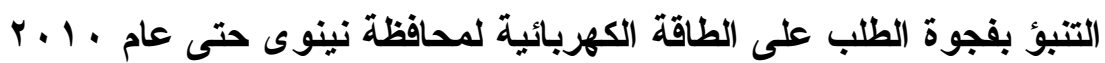

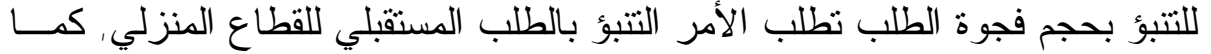

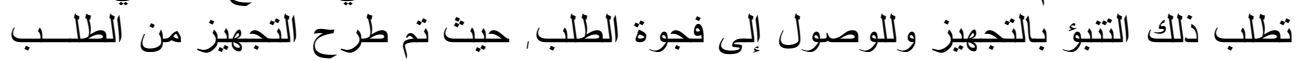

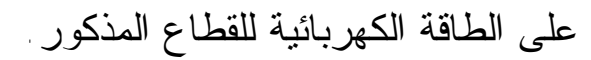

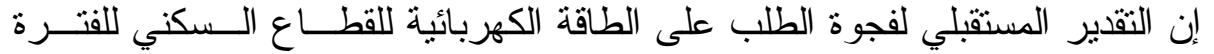

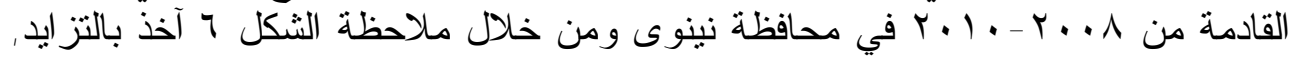

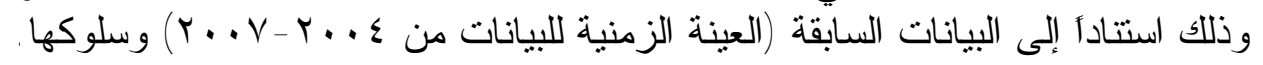

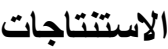

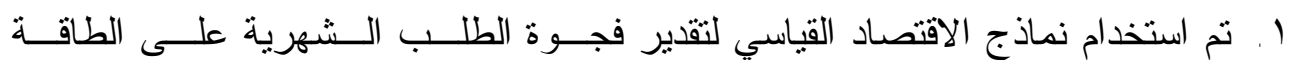

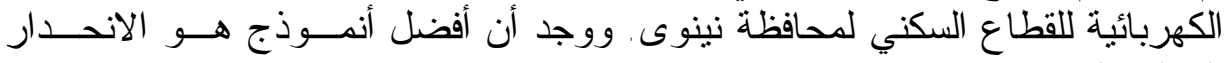

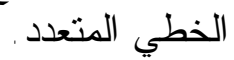

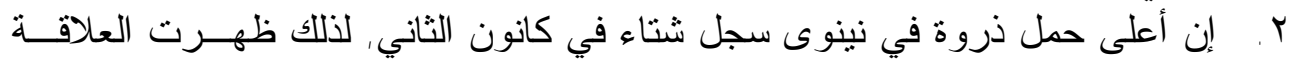

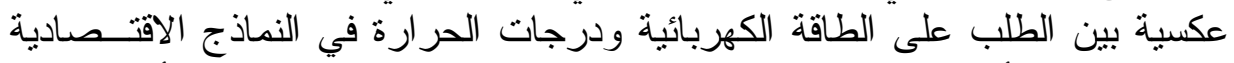

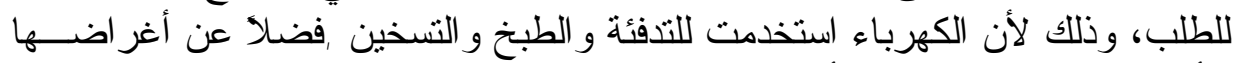

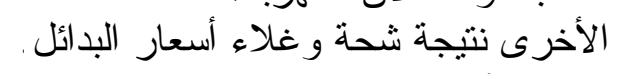

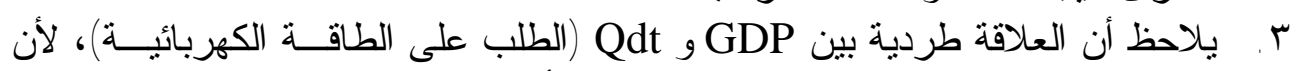

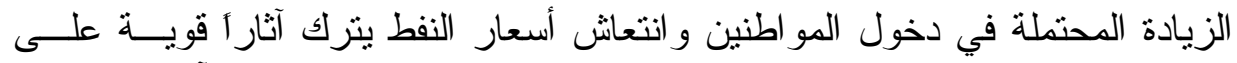

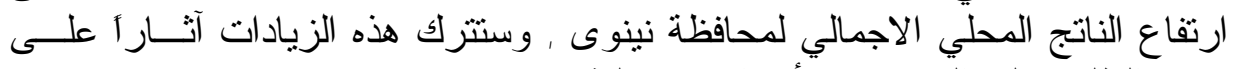

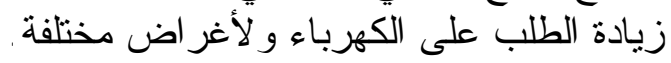

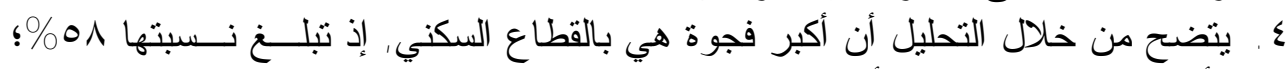

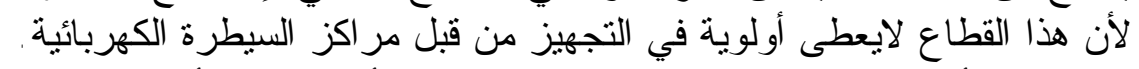

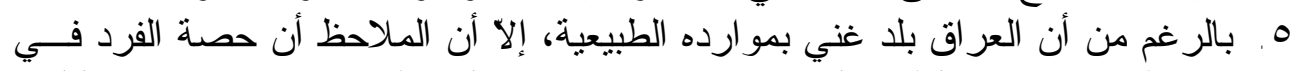

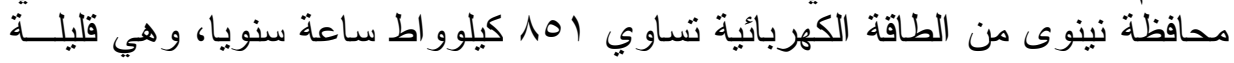

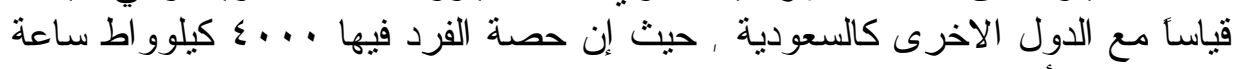

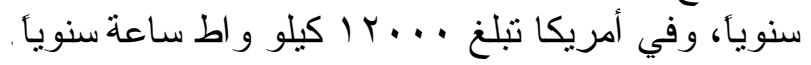

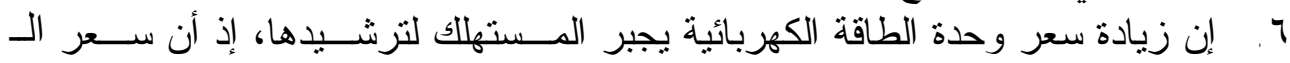

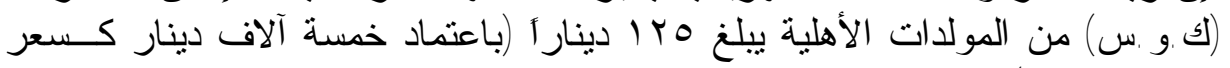

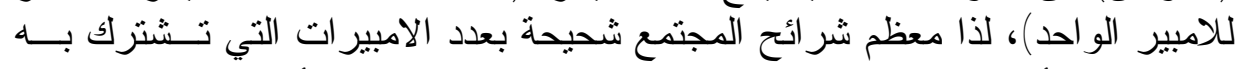

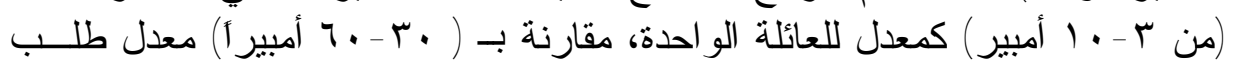

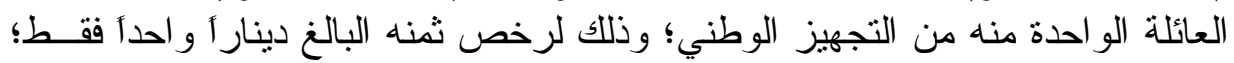

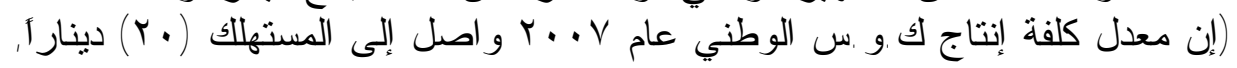




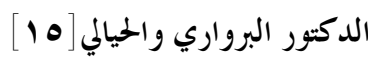

مما يعني أن هنالك دعم حكومي مقداره ( . 19 \%) للشريحة الأولـى مــن القطــاع السكني)، فضلا عن جودة مو اصفاته مقارنة بالبدائل .

\section{(المقترحات}

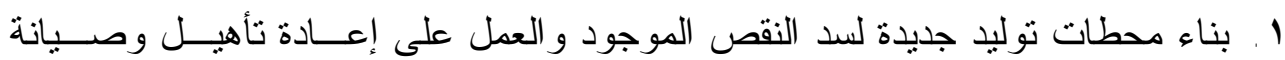

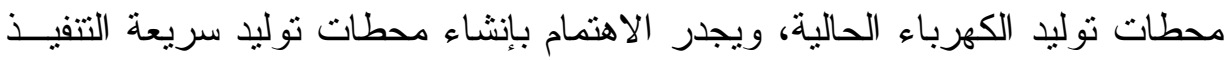
كالمحطات الغازية و البدء بانثاء محطات حرارية كبيرة ولئبة ومحطات كهرومائية كمحطة توليد سد بخمة لتلبية الطلب. r. ترشيد الاستهلاك وزيادة كفاءة استخدام الأجهزة الكهربائية، وزيادة أسـعار الطاقــة الكهربائية لتقليل استهلاكها.

r. استخدام محطات شمسية ومز ارع الرياح و السدود المائية التي تعد صديقة للبيئة لتوليد

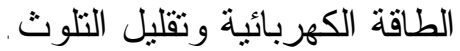
ء. ـ استخدام المولدات الأهلية في محطات توليد الكهرباء وبالاعتماد على الخطوط الوطنية

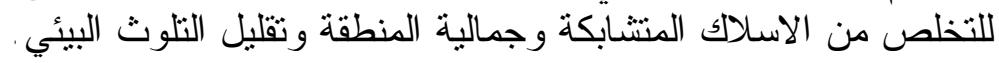

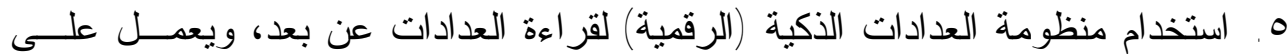

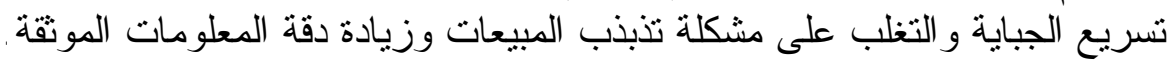




\section{الجدول}

معدل القدرة الكهربائية Mw المطلوبة والمجهزة والفجوة وعدد المشتركين

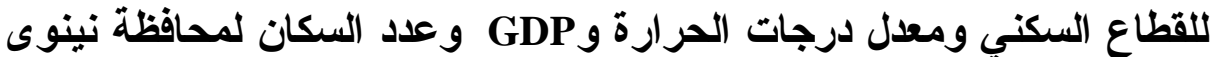

\begin{tabular}{|c|c|c|c|c|c|c|c|c|}
\hline سكان & GDP & Temp & مشسئر كين & فجوة المنز ثي & ائمجهز & انطظب & Num & أسذةً \\
\hline 2580633 & 374.56 & 8 & 249656 & 239.55 & 150.71 & 394.4 & 1 & 2004 \\
\hline 2587540 & 375.56 & 9.1 & 249975 & 230.98 & 141.8 & 376.8 & 2 & \\
\hline 2594447 & 376.56 & 13.9 & 250693 & 258.77 & 102.37 & 365 & 3 & \\
\hline 2601354 & $\mathbf{3 7 7 . 5 7}$ & 17.9 & 251495 & 87.03 & 268.28 & 359.1 & 4 & \\
\hline 2608261 & 378.57 & 24.3 & 251939 & 113.32 & 253.65 & 370.9 & 5 & \\
\hline 2615168 & 379.57 & 31.3 & 252739 & 170.45 & 208.16 & 382.7 & 6 & \\
\hline 2622075 & 380.57 & 34.1 & 253317 & 169.24 & 221.02 & 394.4 & 7 & \\
\hline 2628982 & 381.58 & 33.2 & 253911 & 237.74 & 146.7 & 388.6 & 8 & \\
\hline 2648644 & 384.43 & 28.7 & 254197 & 229.05 & 143.74 & 376.8 & 9 & \\
\hline 2657853 & $\mathbf{3 8 5 . 7 7}$ & 23.5 & 254950 & 217.68 & 143.46 & 365 & 10 & \\
\hline 2667045 & 387.1 & 13 & 255157 & 207.16 & 171.45 & 382.7 & 11 & \\
\hline 2674014 & 388.11 & 9 & 255351 & 222.02 & 174.07 & 400.3 & 12 & \\
\hline 2673086 & 392.9 & 7.4 & 255828 & 293.48 & 152.51 & 447.4 & 13 & 2005 \\
\hline 2675949 & 393.32 & 8.7 & 256106 & 287.59 & 137.87 & 426.8 & 14 & \\
\hline 2681094 & 394.07 & 13.8 & 256719 & 160.25 & 235.86 & 397.4 & 15 & \\
\hline 2685969 & 394.79 & 19.8 & 257199 & 59.35 & 327.96 & 388.6 & 16 & \\
\hline 2685578 & 394.73 & 24.9 & 257563 & 254.17 & 150.74 & 406.2 & 17 & \\
\hline 2692524 & 395.75 & 30.5 & 258177 & 272.96 & 146.63 & 420.9 & 18 & \\
\hline 2699006 & 396.71 & 35.1 & 258625 & 298.3 & 153.56 & 453.3 & 19 & \\
\hline 2703212 & 397.32 & 34.5 & 259328 & 288.54 & 151.58 & 441.5 & 20 & \\
\hline 2709447 & 398.24 & 28.6 & 259696 & 276.78 & 134.01 & 412.1 & 21 & \\
\hline 2714683 & 399.01 & 21.7 & 260314 & 245.39 & 156.59 & 403.3 & 22 & \\
\hline 2719486 & 399.72 & 13.4 & 260983 & 232.92 & 183.73 & 418 & 23 & \\
\hline 2725010 & 400.53 & 10.7 & 261758 & 279.42 & 157.77 & 438.6 & 24 & \\
\hline 2731776 & 410.11 & 7.2 & 262393 & 410.45 & 137.32 & 547.5 & 25 & 2006 \\
\hline 2739364 & 411.25 & 10.5 & 262975 & 384.56 & 145.55 & 529.8 & 26 & \\
\hline 2747419 & 412.46 & 14.6 & 263710 & 340.22 & 157.49 & 497.5 & 27 & \\
\hline 2757918 & 414.04 & 19.2 & 264316 & 298.34 & 190.53 & 488.6 & 28 & \\
\hline 2767703 & 415.51 & 25.7 & 264909 & 326.73 & 179.82 & 506.3 & 29 & \\
\hline 2774581 & 416.54 & 32.7 & 265461 & 347.88 & 170.45 & 518.1 & 30 & \\
\hline 2782096 & 417.67 & 34.3 & 266230 & 373.85 & 168.03 & 541.6 & 31 & \\
\hline 2792492 & 419.23 & 35.9 & 266918 & 379.51 & 156.49 & 535.7 & 32 & \\
\hline 2801694 & 420.61 & 28.1 & 267380 & 360.67 & 151.76 & 512.2 & 33 & \\
\hline 2808356 & 421.61 & 22.8 & 268039 & 329.32 & 165.44 & 494.5 & 34 & \\
\hline 2814097 & 422.47 & 11.6 & 268494 & 30 & 211.47 & 521 & 35 & \\
\hline 2828742 & 424.67 & 6.5 & 269152 & 360.06 & 175.94 & 535.7 & 36 & \\
\hline 2838087 & 433.88 & 7.6 & 269754 & 510.46 & 145.75 & 653.5 & 37 & 2007 \\
\hline 2842516 & 434.55 & 9.6 & 270284 & 498.27 & 128.38 & 624 & 38 & \\
\hline 2847075 & 435.25 & 14.4 & 270742 & 421.09 & 181.92 & 600.5 & 39 & \\
\hline 2853036 & 436.16 & 19 & 271456 & 379.49 & 174.45 & 551.6 & 40 & \\
\hline 2859962 & 437.22 & 25.8 & 272043 & $\mathbf{3 1 7 . 7 7}$ & 202.47 & 518.1 & 41 & \\
\hline 2868773 & 438.57 & 32.5 & 272529 & $\mathbf{3 4 4 . 9 1}$ & 201.93 & 544.6 & 42 & \\
\hline 2875714 & 439.63 & 36.1 & 272883 & 386.63 & 180.9 & 565.2 & 43 & \\
\hline 2881881 & 440.57 & 35.3 & 273264 & 409.13 & 170.22 & 576.9 & 44 & \\
\hline 2889130 & 441.68 & 29.9 & 273791 & 344.28 & 158.23 & 500.4 & 45 & \\
\hline 2894915 & 442.56 & 23.1 & 274217 & 326.11 & 170.48 & 494.5 & 46 & \\
\hline 2901111 & 443.51 & 13.7 & 274793 & 351.54 & 198.26 & 547.5 & 47 & \\
\hline 2912137 & 445.2 & 8.6 & 275358 & 434.32 & 153.91 & 585.8 & 48 & \\
\hline
\end{tabular}

المصدر: الجدول من إعداد الباحثان بالاعتماد على بيانات مبيعات الطاقة الكهربائية مــن توزيع نبنوى و الطلب عليها من مديرية نقل الطاقة الثمالية. 


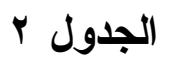

الطاقة الكهربائية Mwh المطلوبة والمجهزة و الفجوة للقطاع السكني

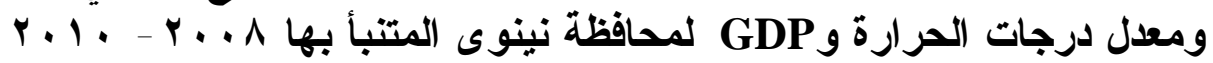

\begin{tabular}{|c|c|c|c|c|c|c|c|}
\hline أفجوة & الوجهميز & |نطب & GDP & Temp & Num & اثتهري & |ائسية | \\
\hline 349972 & 98504 & 448476 & 446.91 & 8.3 & 49 & Jan & 2008 \\
\hline 341540 & 84400 & 425940 & 448.5 & 10.15 & 50 & Feb & \\
\hline 323354 & 34096 & 457450 & 450.09 & 4.85 & 51 & Mar & \\
\hline 297599 & 44892 & 442491 & 51.68 & 6 & 52 & Apr & \\
\hline $\mathbf{3 1 7 7 7 7}$ & 137188 & 454965 & 53.27 & 38 & 53 & Vay & \\
\hline 313046 & 123884 & 436930 & 454.86 & 2.41 & 54 & Jun & \\
\hline 325327 & 124380 & 449707 & 456.45 & 35.53 & 55 & Jul & \\
\hline 345052 & 105876 & 450928 & 458.04 & $\mathbf{3 5 . 3 5}$ & 56 & Aug & \\
\hline 347763 & 94872 & 442635 & \begin{tabular}{|l|l|}
459.63 \\
\end{tabular} & 29.47 & 57 & Sep & \\
\hline 357776 & 108668 & 466444 & 461.22 & 3.5 & 58 & Oct & \\
\hline 331827 & 132064 & 463 & & & 59 & Nov & \\
\hline 378480 & 111760 & 490240 & 4 & .54 & bu & Dec & \\
\hline 400839 & 97256 & 498095 & 465.99 & 57 & 61 & $\operatorname{Ian}$ & 2009 \\
\hline 370825 & 83152 & 453977 & 467.58 & 10.42 & 62 & Feb & \\
\hline 370786 & 132848 & 503634 & 469.17 & 15.12 & 63 & Mar & \\
\hline 343021 & 43644 & 486665 & & 19.93 & 64 & Apr & \\
\hline 364412 & 35940 & 500352 & & & 65 & Iay & \\
\hline 358095 & 122636 & 480731 & 4 & & 66 & Iun & \\
\hline 371776 & 123132 & 494908 & .53 & 3 & 67 & Jul & \\
\hline 391472 & 104628 & 496100 & 477.12 & 35.62 & 68 & Aug & \\
\hline 392712 & 93624 & 486336 & 478.71 & 29.74 & 69 & Sep & \\
\hline 404175 & 107420 & 511595 & 480.3 & 23.77 & 70 & Det & \\
\hline 376767 & 130816 & 507583 & 481.89 & 13.87 & 71 & Nov & \\
\hline 424874 & 110512 & 535386 & 483.48 & 9.8 & 72 & Dec & \\
\hline 447232 & 08 & 543 & & & 73 & $\operatorname{lan}$ & 201 \\
\hline 412849 & 81904 & 494753 & \begin{tabular}{|l|}
486.66 \\
\end{tabular} & 10.69 & 74 & eb & \\
\hline 417179 & 131600 & 548779 & 488.25 & 39 & 75 & Mar & \\
\hline 387957 & 142396 & 530353 & \begin{tabular}{|l|}
489.84 \\
\end{tabular} & 20.2 & 76 & Apr & \\
\hline 410804 & 134692 & 545496 & 491.43 & 26.42 & 77 & May & \\
\hline 403031 & 121388 & 524419 & 493.02 & 32 & 78 & Jun & \\
\hline 418169 & 121884 & 540053 & & & 79 & ul & \\
\hline 437865 & 103380 & 541245 & & & 80 & Aug & \\
\hline 437649 & 92376 & 530025 & 497.79 & 30.01 & 81 & Sep & \\
\hline 450567 & 106172 & 556739 & 499.38 & 24.04 & 82 & Oct & \\
\hline 421703 & 129568 & 551271 & 500.97 & 14.14 & 83 & Nov & \\
\hline 471267 & 109264 & 580531 & 502.56 & 10.08 & 84 & Dec & \\
\hline
\end{tabular}

المصدر : الجدول من إعداد الباحثًان و البيانات التي تم التنبؤ بها. 


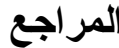

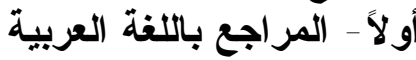

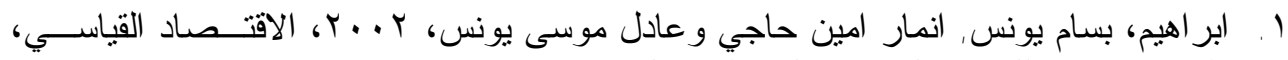

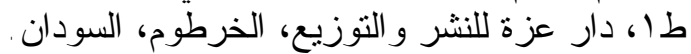

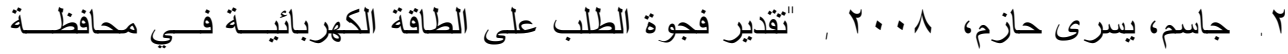

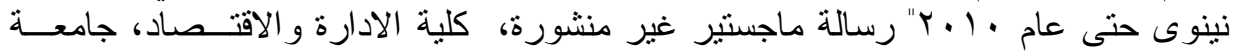

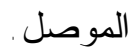

r. الجهاز المركزي للاحصاء في محافظة نينوى التابع لوز ارة التخطيط.

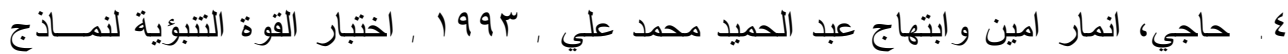

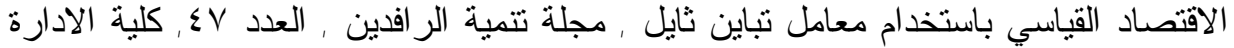
و الاقتصاد, جامعة الموصل.

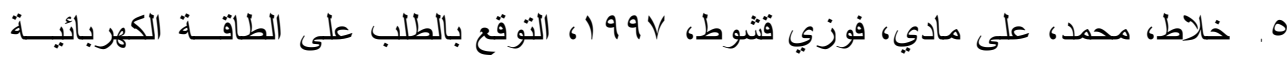

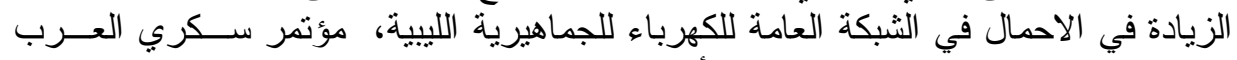

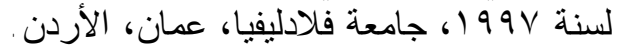

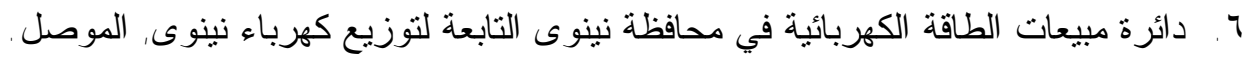

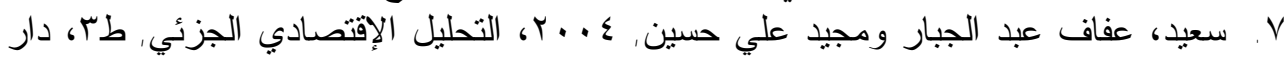

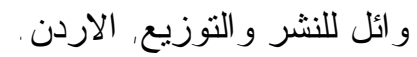

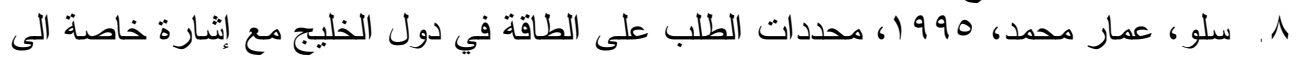

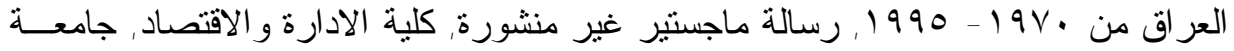

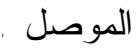

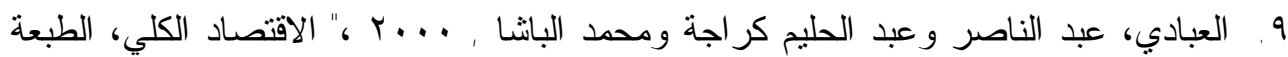

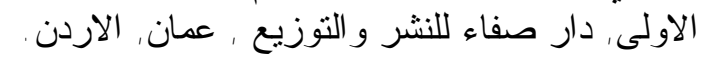

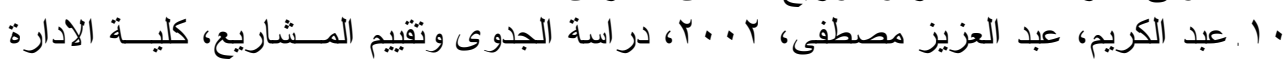

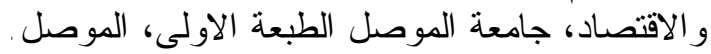

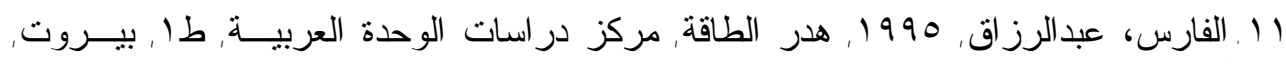

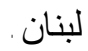

r ا .فينارد، إدوين، إدارة أعمال الطاقة الكهربائية، ترجمة محمد عبدالرحمن الحبدر، طا ا، مطابع

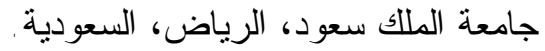

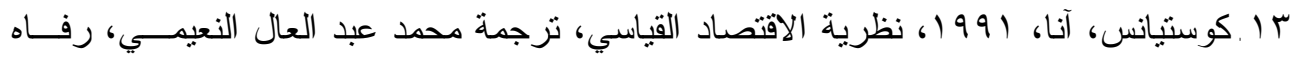

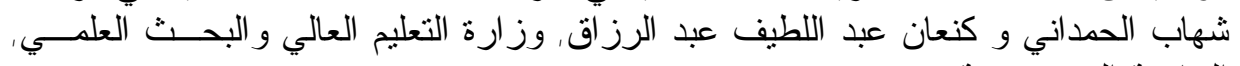
الجامعة المستتصرية.

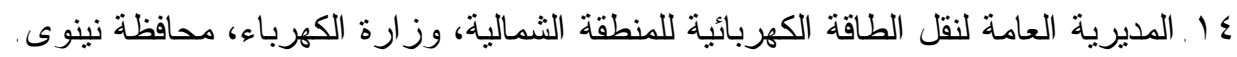

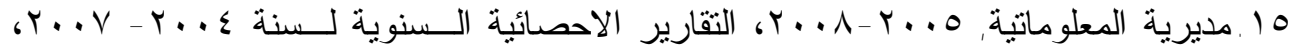

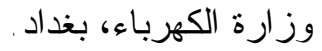

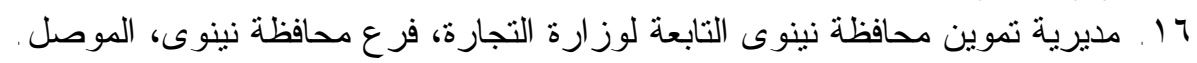

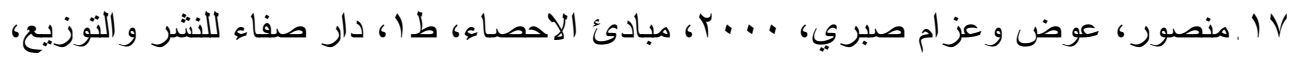

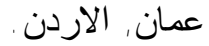

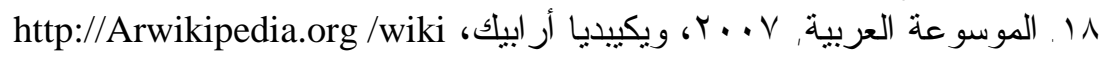


الدكتور البرواري والحيالي[ [1 ][

ثانياً - المر اجع باللغة الاجنبية

1.United Nations Statistics Division - National Accounts, 2006, Iraq - Aavailable Series, http://unstats.un.org/unsd/snaama/United Nations Statistics Division National Accounts.htm .

2. Shona Kohler, 2008, National electricity supply shortage sets in, South Africa, http://www.engineeringnews.co.za/author.php?u_id=54.

3. Simonj Watson and Shanti Majithia, 2005, Analyzing the Impact of Weather Variables on Monthly Eelectricity Demand, Ching-lai Hor, member, IEEE, IEE Transactions on power systems, Vol. 20, No.4, Nov.

4.Paul A. Samuelson \& William D. Nordhaus, 1985, Economics, $12^{\text {th }}$ edition, McGraw-Hill Comp. Singapore.

5. Spyros Makridakis, Steven C. wheelwright, and Victore E. Mcgee, 1983, Forecasting: Methods and Aplications, $2^{\text {nd }}$ edition, John Wiey\& Sons, USA.

6. Mclaren C. H. and Mclaren B. J., 2003, "Electric bill data", Journal of Statistics Education [online], No. 11(1),

www.amstat.org/publications/jse/v11n1/datasets.mclaren.html. 